\title{
Effect of voltage waveform on dielectric barrier discharge ozone production efficiency
}

\author{
N. Mericam-Bourdet ${ }^{1,2}$, M.J. Kirkpatrick ${ }^{2}$, F. Tuvache ${ }^{1}$, D. Frochot ${ }^{1}$ and E. Odic ${ }^{2}$ \\ ${ }^{1}$ EDF R\&D - EPI Dpt - Les Renardières, 77250 Moret-sur-Loing, France \\ ${ }^{2}$ SUPELEC - E3S Département Electrotechnique et Systèmes d'Energie, 91192 Gif-sur-Yvette \\ Cedex, France
}

Corresponding author: Emmanuel Odic

Email: emmanuel.odic@supelec.fr

Pacs numbers : 52.80-sElectrical discharges, 52.77.-jPlasma applications

Key Words: dielectric barrier discharge; ozone production; energy efficiency; voltage waveform

Short title: Effect of voltage waveform on DBD ozone production efficiency

\begin{abstract}
Dielectric barrier discharges (DBD) are commonly used for gas effluent cleanup and ozone generation. For these applications, the energy efficiency of the discharge is a major concern. This paper reports on investigations carried out on the voltage shape applied to DBD reactor electrodes, aiming to evaluate a possible energy efficiency improvement for ozone production. Two DBD reactor geometries were used; pin-to-pin and cylinder-to-cylinder, both driven either by a bi-directional power supply (voltage rise rate $1 \mathrm{kV} / \mu \mathrm{s}$ ) or a pulsed power supply (voltage rise rate $1 \mathrm{kV} / \mathrm{ns}$ ). Ozone formed in dry air was measured at the reactor outlet. Special attention was paid to discharge input power evaluation using different methods including instantaneous current-voltage product and transferred charge-applied voltage figures. The charge transferred by the discharges was also correlated to the ozone production. It is shown that, in the case of the DBD reactors under investigation, the applied voltage shape has no influence on the ozone production efficiency. For the considered voltage rise rate, the charge deposit on the dielectric inserted inside the discharge gap is the important factor (as opposed to the voltage shape) governing the efficiency of the discharge - it does this by tailoring the duration of the current peak into the tens of nanoseconds range.
\end{abstract}




\section{Introduction}

The use of dielectric barrier discharges (DBDs) is a common way to produce atmospheric pressure non-thermal plasmas as a source of chemically reactive species, without arcing. Non-thermal plasma discharges have been investigated for a wide range of applications such as gas effluent cleanup [1, 2 , $3]$, UV light production [4, 5], surface treatment $[6,7]$ and ozone generation [8, 9]. For these processes, the energy efficiency of the plasma process is a major concern and often needs to be improved to attain economic viability. Many attempts have been made in the past to increase the efficiency of dielectric barrier discharges for ozone production or for gas phase pollutant removal. Factors which have been considered in these studies include the influence of the addition of argon [10], the influence of dielectric material [11], electrode shape [12, 13] or discharge regime [14]. The most intensive work aimed to increase the efficiency of dielectric barrier discharges concerns the electrical power supply and specifically the high voltage signal waveform used, typically either AC or pulsed, with in the latter case special attention to the pulse shape (rise rate, duration). In the case of corona discharges (asymmetric electrode arrangement without dielectric), the shortening of the pulse duration and the increase of the voltage rise rate have a clear effect on the energy efficiency of the discharge as shown in [15] and [16] where ozone production is shown to be improved. In the presence of a dielectric barrier, results found in the literature are less than unanimous. When short voltage pulses are used instead of ac voltage, an improvement of the energy efficiency is claimed for ozone production $[17,18,19,20]$ and VOC removal [21] whereas other authors observed no effect of the voltage shape on methane conversion energy efficiency [22] and more generally air pollutant removal efficiency [23]. The work reported in this paper is an attempt to clarify the impact of the voltage shape on the chemical reactivity of DBDs. Two types of reactor geometry and voltage waveforms were tested for the production of ozone from dry air. For both geometries, the effect of voltage signal frequency was investigated. In order to evaluate the energy efficiency for each power supply/DBD reactor combination, special attention was paid to the measurement of discharge input power.

\section{Experimental setup}

Two DBD reactors were used for the experiments. The first reactor has a multiple pin-to-pin geometry with a dielectric plate (mica/epoxy resin plate, $20 \mathrm{kV} / \mathrm{mm}$ dielectric strength, $\varepsilon_{\mathrm{r}} \sim 5,1 \mathrm{~mm}$ thickness) centered in the gap between the pin electrodes. The distance between the point tip and the plane dielectric surface was $1 \mathrm{~mm}$. The number of discharge sites in the reactor was fixed by the number of pins. On either side of the dielectric plate, these pins were organized in a linear array (in the direction of the flow) of equidistant groups of 4 pins. The number of groups was varied from 4 to 
26 (16 and 104 pins respectively). In the specific case of 104 pins, a double array of 13 groups of pins was used. According to the number of pins, the active length of the reactor ranged from $33 \mathrm{~mm}$ to $163 \mathrm{~mm}$. The second reactor had a typical ozonizer-type coaxial cylinder-to-cylinder geometry. The high voltage electrode was a stainless steel cylinder with a $19 \mathrm{~mm}$ outer diameter, centered within a dielectric tube (Pyrex tube, $3 \mathrm{~mm}$ thickness, $14 \mathrm{kV} / \mathrm{mm}$ dielectric strength, $\varepsilon_{\mathrm{r}} \sim 4.7,22 \mathrm{~mm}$ inner diameter). The gas gap between the outer surface of the high voltage electrode and the inner surface of the dielectric tube was $1.5 \mathrm{~mm}$. A grounded counter electrode, wrapped on the outer surface of the dielectric, delimited the discharge region length to $70 \mathrm{~mm}$. Contrary to the pin-to-pin reactor, the distribution of discharge filaments was self-organized in the gas gap of the cylinder reactor.

For a $2 \mathrm{~L} / \mathrm{min}$. flow rate entering the reactor inlet, the mean residence time in the active volume of the discharge reactor was $20 \mathrm{~ms}$ in the case of the cylinder-to-cylinder geometry and ranged from $9 \mathrm{~ms}$ to $45 \mathrm{~ms}$ in the case of the multi-pins reactor. Figure 1 presents schematic representations and photographs of the two reactors.

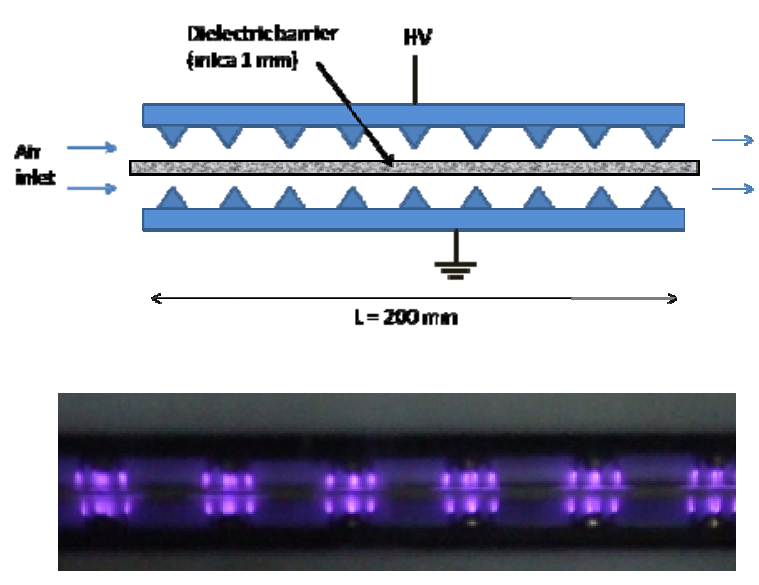

(a)
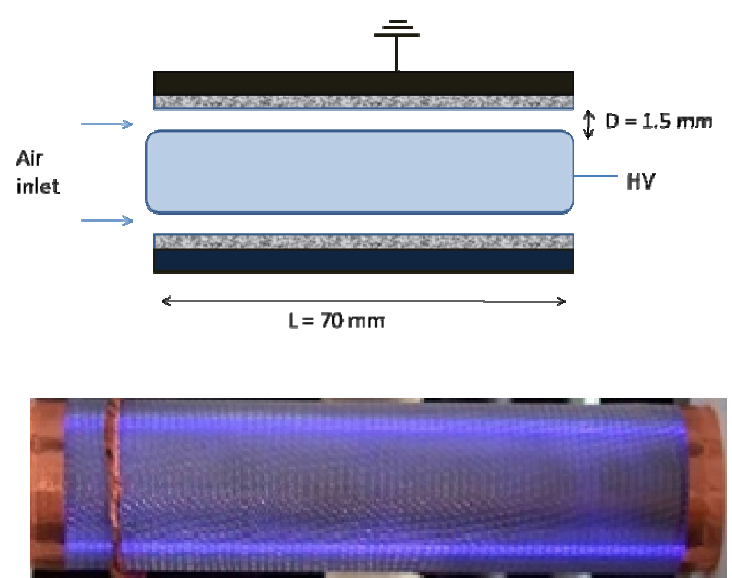

(b)

Figure 1. Schematics and photographs of the plasma reactors (a) pin-to-pin DBD reactor, (b) co-axial cylinderto-cylinder DBD reactor.

Reactors were powered either by a bi-directional high voltage supply or by a pulsed high voltage source. Comparisons were also made with a classic $50 \mathrm{~Hz}$ sinusoidal generator. Figure 2 shows the voltage and current waveforms for the two main power supplies. The maximum voltage for the pulsed excitation (up to $25 \mathrm{kV}$ ) is higher than for the bi-directional power supply (11kVmax). Current waveforms are quite different. The current in the bi-directional case consists of a series of small peaks (few hundreds of $\mathrm{mA}$ in Figure 2-b) with a high repetition rate spread out over 1 or $1.5 \mu \mathrm{s}$, superimposed on a low amplitude arch signal corresponding to the displacement current. Each current peak corresponds to a single or maximum two to three filaments crossing the gap. 
With the pulsed power supply, due to the high rise rate of the voltage and to the capacitance of the reactor, high amplitude displacement current peaks are visible at the rise and at the fall of the voltage pulse (Figure 2-c). In absence of a discharge, these peaks are obviously also observed. When the amplitude of the voltage plateau is high enough for gas breakdown (inception voltage is reached), a single positive current peak (a zoomed in view of the current peaks is given in Figure 2-d) with a much higher amplitude (tens of amperes) is observed to occur after the first displacement current peak. During the discharge, filaments are formed at each point electrode, and quasisimultaneously propagate in the gas gap. This current peak lasts around 40 to 50 ns. The time elapsed between the beginning of the voltage pulse and the appearance of the discharge is in some conditions rather unstable - discharges can be initiated seemingly randomly during the entire duration of the voltage pulse.

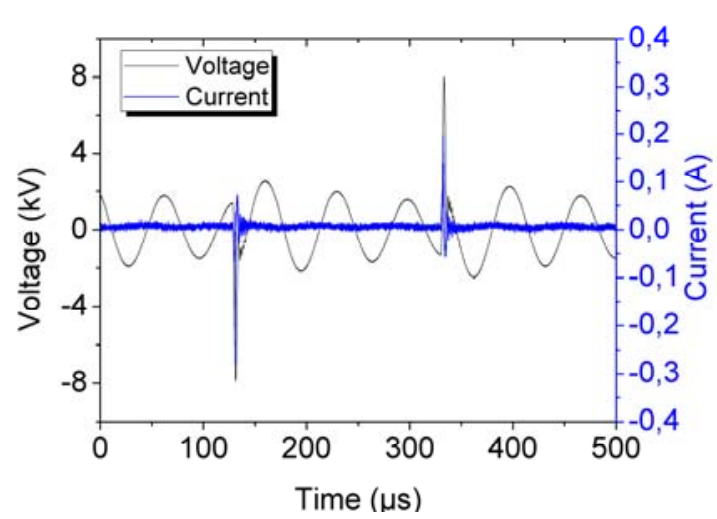

(a)

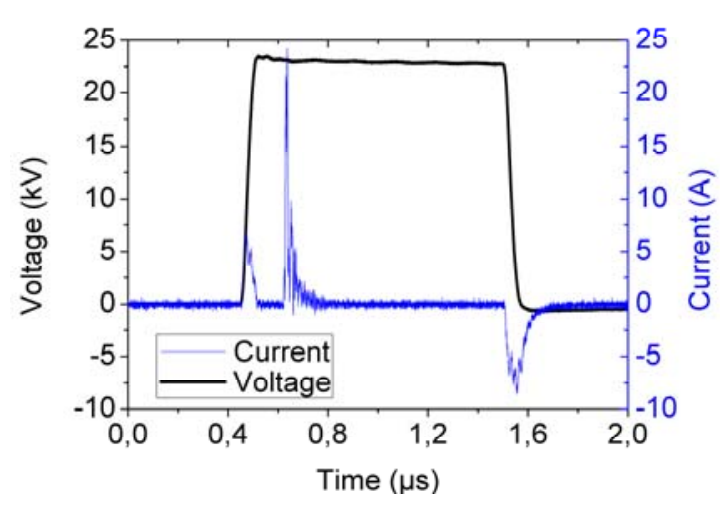

(c)

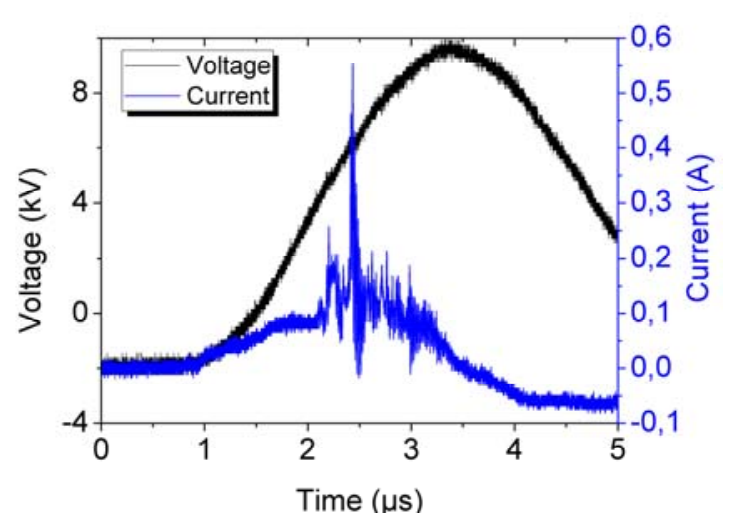

(b)

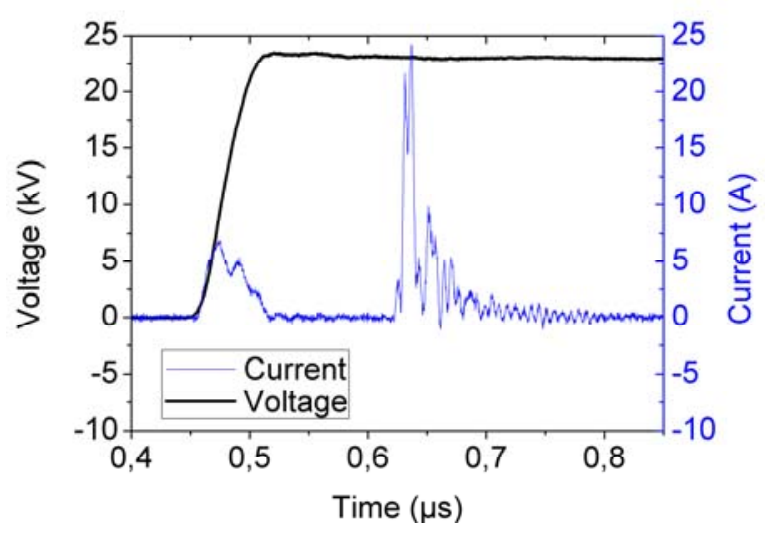

(d)

Figure 2. Voltage and current waveforms obtained with the bi-directional power supply (a-b) and pulsed power supply (c-d) coupled with the pin-to-pin DBD reactor. 
When the voltage drops back to zero, the charge deposit on the dielectric surface leads to a local electric field enhancement and to a second gas breakdown (with a rather low amplitude negative current peak, superimposed over the negative displacement current). This point will be further discussed later on.

The bi-directional power supply consisted of an IGBT full bridge connected to the primary winding of a high voltage transformer. Frequency was in the range of $300 \mathrm{~Hz}$ to $30 \mathrm{kHz}$ and peak voltage could be set up to $11 \mathrm{kV}$. The voltage rise rate was $1 \mathrm{kV} / \mu \mathrm{s}$ (Fig. $2 \mathrm{a}-\mathrm{b}$ ) and did not depend on the frequency. A similar power supply was previously used for investigations on (i) point-to-plane DBD ozone generation [24] and (ii) DBD treatment of dilute methane [25]. The pulsed power supply was constructed using a MOSFET solid switch bridge (Behlke HTS 301) with a $1 \mathrm{nF}$ charging capacitor fed by a dc $30 \mathrm{kV}-10 \mathrm{~mA}$ high voltage power source. Positive voltage pulses of up to $25 \mathrm{kV}$ and $800 \mathrm{~ns}$ width were obtained. The voltage pulse rise time was $1 \mathrm{kV} / \mathrm{ns}$ (Fig. $2 \mathrm{c}-\mathrm{d}$ ). The frequency was tunable from a few hertz to $2 \mathrm{kHz}$.

A Tektronix P6015A (1V:1000V - 75MHz) and a Tektronix CT-2 current transformer (1mV:1mA $200 \mathrm{MHz}$ ) were used for voltage and current measurements, respectively. Signals were recorded by a LeCroy WaveRunner $62 \mathrm{Xi}$ digital oscilloscope $(600 \mathrm{MHz}-10 \mathrm{GS} / \mathrm{s})$. The discharge input power was calculated using two different methods for both power supplies: firstly, by using the instantaneous voltage-current product method, and secondly, by the method of determination of the Lissajous figure area.

All experiments were conducted in synthetic dry air at atmospheric pressure. The gas (synthetic air) flow rate was fixed at either 1 or $2 \mathrm{~L} / \mathrm{min}$. Gas phase chemical measurements were performed at the discharge reactor outlet by absorption spectroscopy, using in series both a Bruker Tensor 27 FTIR $\left(0.5 \mathrm{~cm}^{-1}\right.$ spectral resolution, with a $20 \mathrm{~cm}$ path length gas cell), and a Perkin Elmer Lambda 15 UV/Vis spectrophotometer (with a $10 \mathrm{~cm}$ path length gas cell). Ozone concentration was first evaluated by monitoring the UV Hartley absorption band (254 nm) when the discharge was running in given operating conditions. When the steady state was obtained (constant discharge input power and constant value of the $254 \mathrm{~nm}$ absorption band), 32 FTIR spectra were accumulated. The ozone concentration was then confirmed (absorption band at $1050 \mathrm{~cm}^{-1}$ ) and nitrogen oxides could be identified and quantified. An example of FTIR spectrum is given in Figure 3, corresponding to experimental data presented in Figure 13 and discussed later on. It should be noted that the formation of small amount of $\mathrm{HNO}_{3}(\sim 5 \mathrm{ppm})$ and the presence of water absorption peaks is due to water traces in the gas line and reactor. 


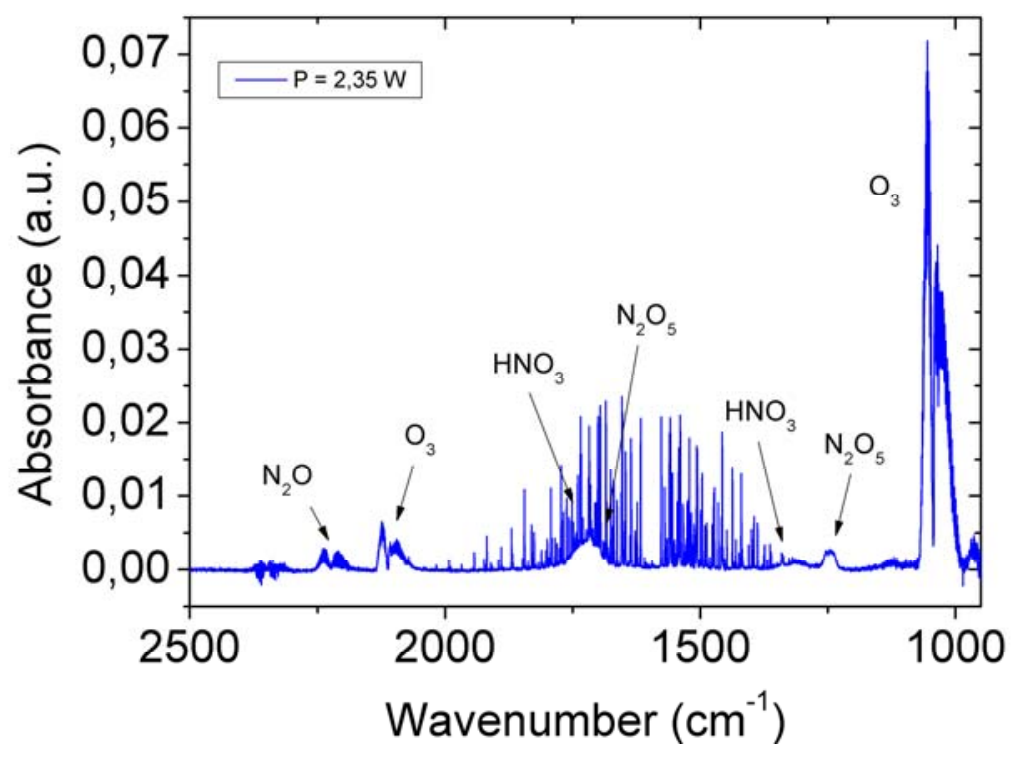

Figure 3. FTIR spectrum obtained at the pin-to-pin discharge reactor outlet, with the bi-directional power supply $(2.35 \mathrm{~W}, \mathrm{f}=3685 \mathrm{~Hz})$; dry air $2 \mathrm{~L} / \mathrm{min}$.

\section{Results and discussion}

\subsection{Power and charge measurements}

The determination of the electrical power deposited in the plasma is a critical issue for the evaluation of the energy efficiency of the plasma process. Uncertainty in the electrical power comes both from the measurement of the voltage and current and from the calculation of the power from those measurements.

Two different methods were used to calculate the plasma energy deposit from the measured voltage and current. The first method was the integration of the instantaneous product of the voltage and current, provided the sample rate of the oscilloscope was high enough to record every current peak. The second method was the V-Q Lissajous figure method where a measurement capacitor (1000$4700 \mathrm{pF}$ ), inserted between the reactor counter electrode and the ground) was used to integrate the current. Using such a method, because the current is integrated physically, the accuracy of the measurement is not dependant on the current probe band pass and oscilloscope sample rate.

For the bi-directional and ac- $50 \mathrm{~Hz}$ power supplies, power measurements performed using the two methods were found to be in good agreement (within $5 \%$ ); the V-Q method was therefore systematically used for the experiments conducted with these power supplies. An example of a 
Lissajous figure is given in Figure 4, corresponding to $4 \mathrm{~W}$ input power dissipated in the pin-to-pin reactor energized by the bi-directional power supply.

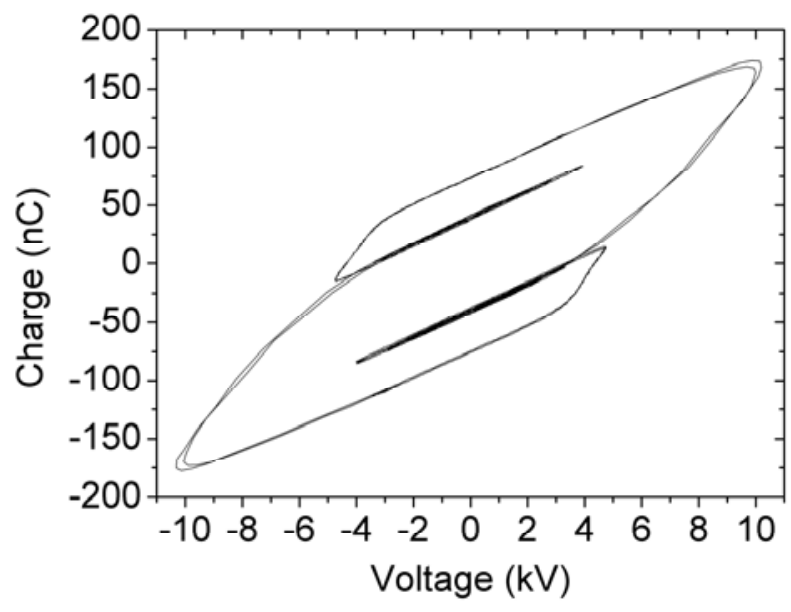

Figure 4. Lissajous figure corresponding to $4 \mathrm{~W}$ input power dissipated in the pin-to-pin reactor (air flow $2 \mathrm{~L} / \mathrm{min}$., bi-directional power supply, $\mathrm{f}=1540 \mathrm{~Hz}$ ).

In the case of the pulse power supply, the power was first measured by the instantaneous voltage current product method. Some precautions have to be considered using this method, such as taking into account the time lag between voltage and current signals due to different delay times associated with each of the two probes (14.7ns and $6.1 \mathrm{~ns}$ for the P6015A voltage probe and the CT2 current probe, respectively). As a consequence of the high rise rate of the voltage, even a small delay between voltage and current signals (here typically $8.6 \mathrm{~ns}$ time lag between the probes) can lead to a large error in the power measurement.

In the absence of a discharge, the power calculated from the product of the voltage pulse and its associated displacement current should be zero. The time lag was adjusted for in the power calculation (by shifting the data of one of the signals with respect to the other, either in an offline calculation, or online using the deskew feature on the oscilloscope) when the reactor was operated with a peak voltage inferior the inception voltage such that the resulting measured power was equal to zero. The resulting time lag was typically about $8.6 \mathrm{~ns}$, precisely in agreement with the manufacturer's data for the two probes. The value of the adjustment made for the time lag was then kept constant for the measurements with discharges.

Figure 5(a) shows an example of an oscillogram obtained using the pulsed power supply. Three distinct current pulses are observed, one during the voltage rise, another during the voltage fall, and another which occurs during the voltage plateau. In order to better understand what is happening physically in the reactor, it is interesting to divide the raw current signal into two parts, the 
displacement current and the discharge current. This is done by calculating the displacement current using $V(t)$ the voltage signal $\left(i_{c}(t)=C \times d V / d t\right)$, where $C$ is the capacitance of the reactor; the discharge current signal is then obtained by subtracting $i_{c}(t)$ from the raw current signal. Figure $5(b)$ shows the two current signals after having been separated in this manner. As can be seen, there are two distinct discharge current pulses, the first positive one has a duration of about $40-60 \mathrm{~ns}$, an amplitude near $25 \mathrm{~A}$, and occurs during the voltage plateau, and the second one is longer (about $100 \mathrm{~ns})$, has a smaller amplitude of about $-7 \mathrm{~A}$, and begins during the voltage fall and even continues afterward. Whether the power is calculated from the raw current data or from the discharge current signal (raw data with the displacement current subtracted), as would be expected, the result is the same provided the time lag is adjusted for. The calculation of the discharge current also enables another value, the total transferred charge, to be determined by integration of the absolute value of the two discharge current peaks. This value is of interest and will be used further on in the discussion.
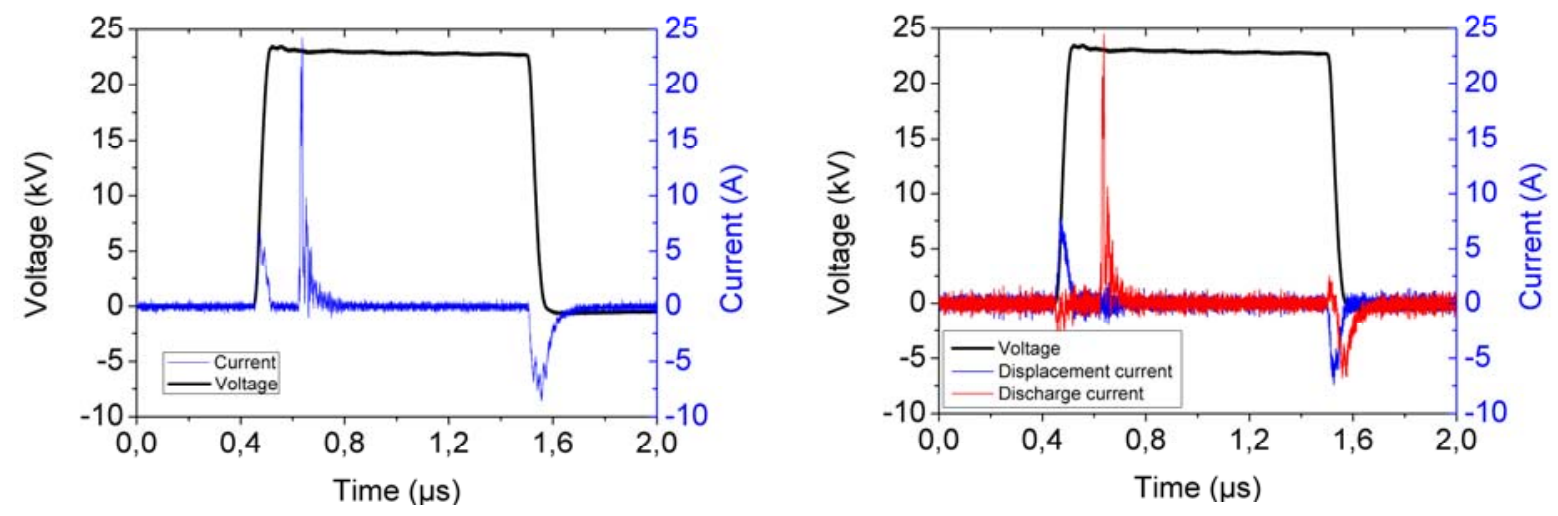

(a)

Figure 5. Current and voltage signals obtained with the pin-to-pin reactor and the pulse power supply (a) and raw current signal divided into its two components, displacement current and discharge current (b).

The power calculated with this method has also been checked by using the V-Q figure method. Even if not systematically used for power evaluation, this method was implemented to compare with the results obtained using the instantaneous voltage - current product method (as for the bi-directional signal). Figure 6-a depicts the waveform of the voltage applied to the reactor and the charge measured by monitoring the capacitor $(4.7 \mathrm{nF})$ voltage. The results were obtained for an intermittent discharge regime (with or without discharge for the same applied voltage value). When a discharge occurs, a step change in the capacitor charge can be clearly seen. When plotting V-Q figures (Figure 6-b), the signals are so noisy that a direct measurement of the figure surface area is not possible. Instead, the position of the four points of the polygon are estimated by taking the average value of $Q$ 
during the stabilized portions of the data seen in Figure 6-a. The first point (1) (voltage: 0 and charge: 0) corresponds to the initial state. A second point (2) corresponds to the positive capacitive charge $(17.5 \mathrm{kV} ; 130 \mathrm{nC})$. These two points are the same as in the Lissajous plot with no discharge. The discharge occurs at constant (maximum) voltage so the increase of the charge is vertical. A third point (3) is found at $17.5 \mathrm{kV}$ and $325 \mathrm{nC}$, corresponding to the charge stored in the measurement capacitor after the positive discharge. The last point (4) corresponds to the situation after the voltage fall toward zero voltage. Calculation of the figure surface gives the energy for one cycle and therefore the power injected in the discharge for a given repetition rate of the voltage pulse. As an example, for the data shown in Figure 6, 2.36mJ of energy input was calculated, while for the same conditions, the instantaneous voltage current product method gave $2.44 \mathrm{~mJ}$.

The use of a capacitor in series with the counter electrode also allows the measurement of the transferred charge: the discharge current peak is seen as a voltage step across the capacitor (plateau value reached after the transient step), proportional to the transferred charge (see Figure 6-a). The positive transferred charge is higher than the negative one. This charge non-equilibrium is exhibited by the non-zero potential observed on the measurement capacitor after the voltage pulse. The transferred charge evaluation using this method, when compared to what was obtained by integrating the discharge current signal (after subtraction of the displacement current signal) led to comparable results. The transferred charge was of interest since ozone was reported to be, for a given discharge reactor geometry, linearly dependent on the transferred charge [24] when gas heating was low.

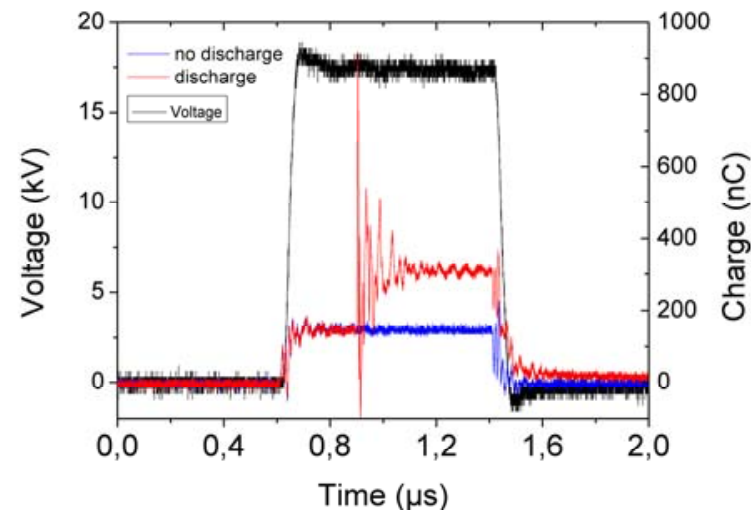

(a)

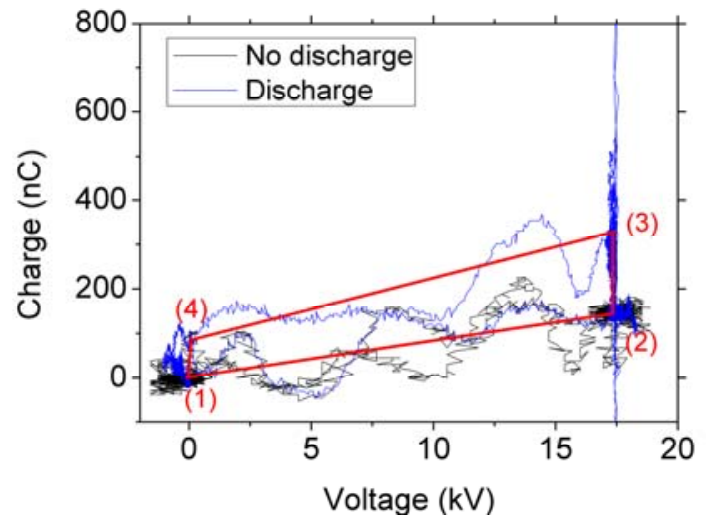

(b)

Figure 6. Applied voltage and charge signals (a) obtained with the pin-to-pin reactor and the pulse power supply (4.7 nF measurement capacitor in series with the counter electrode); (b) corresponding V-Q figure. 
Ozone production efficiency will then be discussed both in terms of discharge specific input energy, i.e. energy deposit per gas volume unit (calculated by the ratio of the discharge input power to the gas flow rate) and in terms of transferred charge.

\subsection{Preliminary study: effect of the reactor geometry and of the applied signal frequency}

To investigate the influence of the reactor geometry on the ozone production efficiency, ozone concentration at the reactor outlet was measured for both reactors, with a fixed air flow rate of $\mathrm{LL} / \mathrm{min}$., and the same power supply (bi-directional voltage source) working with a similar frequency. Furthermore, in the case of the pin-to-pin reactor, the number of pin electrodes was changed from 16 and 104. Results are presented in figure 7. It can be seen that all curves tend to merge into a similar trend, when the number of pin electrodes is increased in the pin-to-pin reactor, so indicating that ozone production efficiency $\left(65-70 \mathrm{gO}_{3} / \mathrm{KWh}\right)$ seems not to be strongly dependent on the reactor geometry in this case. For the cylinder-to-cylinder reactor geometry, the ozone concentration vs. specific energy density curve exhibits a different trend, with lower energy efficiency (45 $\mathrm{gO}_{3} / \mathrm{KWh}$.

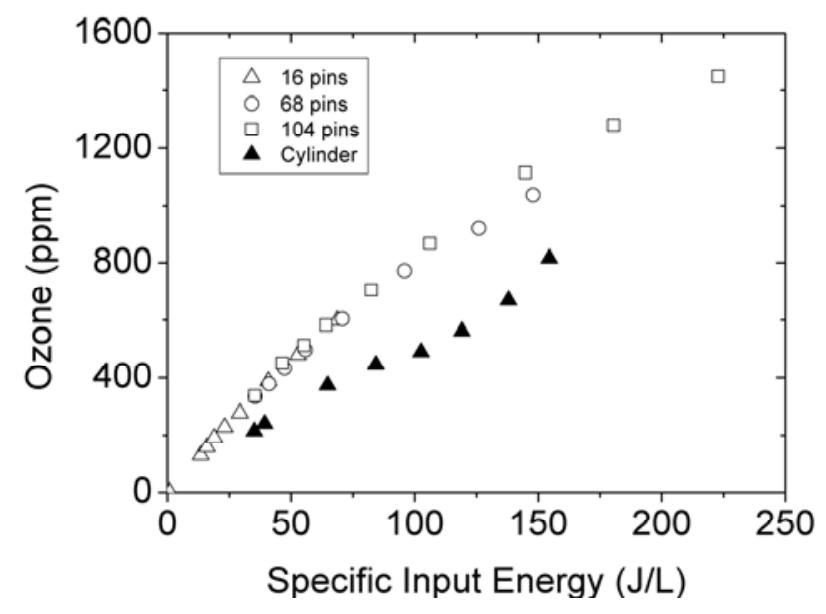

Figure 7. Ozone concentration at the reactor outlet vs. specific input energy, for the cylinder-to-cylinder reactor and for the pin-to-pin reactor (with increasing number of pins from 16 to 104) - air flow: 2 L/min, bi-directional power supply, $1450 \mathrm{~Hz}$ for the pin-to-pin reactor, $1700 \mathrm{~Hz}$ for the cylinder-to-cylinder reactor.

This difference in reactor performance is attributed to different thermal behaviors. According to the rate constants governing the kinetics of ozone formation (see Table 1), increasing the gas temperature will lead to (i) decrease of the ozone formation rate, (ii) increase of the formed ozone decomposition rate and (iii) increase of the nitrogen oxides production rate. The composition of an air discharge effluent at atmospheric pressure was previously investigated [26] showing that, with rising plasma temperature (when increasing the discharge input power), ozone concentration first 
increases, reaches a maximum value, and then decreases below detection limits, while simultaneously nitrogen oxides concentration continuously increases $\left(\mathrm{N}_{2} \mathrm{O}\right.$ and $\mathrm{N}_{2} \mathrm{O}_{5}$ in dry conditions); $\mathrm{NO}_{2}$ appears at the temperature at which ozone concentration begins decreasing, and $\mathrm{NO}$ is only detected for temperatures at which ozone is no longer measured. For a given specific energy density, a higher gas temperature leads to a lower ozone concentration measured at the reactor outlet. At this point, it should be underlined that the discharge reactors were not cooled. Temperature measurements were not made at the reactor walls because the casing of these reactors did not allow such a measurement in identical conditions for both reactors.

Table 1: reactions and rate constants for ozone and nitrogen oxides formation

\begin{tabular}{|c|c|c|}
\hline Process & Rate coefficient & Reference \\
\hline $\mathrm{O}+\mathrm{O}_{2}+\mathrm{M} \rightarrow \mathrm{O}_{3}+\mathrm{M}$ & $\begin{array}{ll}M=O_{2} & k=5.58 \times 10^{-29} \mathrm{~T}^{-2} \mathrm{~cm}^{6} \cdot \mathrm{molec}^{-2} \cdot \mathrm{s}^{-1} \\
\mathrm{M}=\mathrm{N}_{2} & \mathrm{k}=8.6 \times 10^{-31} \mathrm{~T}^{-1.25} \mathrm{~cm}^{6} \cdot \mathrm{molec}^{-2} \cdot \mathrm{s}^{-1}\end{array}$ & $\begin{array}{l}{[27]} \\
{[27]}\end{array}$ \\
\hline $\mathrm{O}+\mathrm{O}+\mathrm{O}_{2} \rightarrow \mathrm{O}_{2}+\mathrm{O}_{2}$ & $\mathrm{k}=(3.8 / \mathrm{T}) \times 10^{-30} \mathrm{~T}^{-1} \exp (-170 / \mathrm{T}) \mathrm{cm}^{6} \cdot \mathrm{molec}^{-2} \cdot \mathrm{s}^{-1}$ & [28] \\
\hline $\mathrm{O}_{2}+\mathrm{O}_{3} \rightarrow \mathrm{O}_{2}+\mathrm{O}_{2}+\mathrm{O}$ & $\mathrm{k}=7.3 \times 10^{-10} \exp (-11400 / \mathrm{T}) \mathrm{cm}^{3} \cdot \mathrm{molec}^{-1} \cdot \mathrm{s}^{-1}$ & [28] \\
\hline $\begin{array}{l}\mathrm{N}+\mathrm{O}_{2} \rightarrow \mathrm{NO}+\mathrm{O} \\
\mathrm{O}+\mathrm{N}+\mathrm{M} \rightarrow \mathrm{NO}+\mathrm{M}\end{array}$ & $\begin{array}{l}\mathrm{k}=4.4 \times 10^{-12} \exp (-3219 / \mathrm{T}) \mathrm{cm}^{3} \cdot \mathrm{molec}^{-1} \cdot \mathrm{s}^{-1} \\
\mathrm{k}=5.46 \times 10^{-33} \pm 4.96 \times 10^{-34} \exp (-1.29 / \mathrm{RT}) \mathrm{cm}^{6} \cdot \mathrm{molec}^{-2} \cdot \mathrm{s}^{-1}\end{array}$ & $\begin{array}{l}{[29]} \\
{[30]}\end{array}$ \\
\hline $\mathrm{N}+\mathrm{O}_{3} \rightarrow \mathrm{NO}+\mathrm{O}_{2}$ & $\mathrm{k}=1.0 \times 10^{-16} \mathrm{~cm}^{3} \cdot \mathrm{molec}^{-1} \cdot \mathrm{s}^{-1}$ & [29] \\
\hline $\mathrm{NO}+\mathrm{O}_{3} \rightarrow \mathrm{NO}_{2}+\mathrm{O}_{2}$ & $\mathrm{k}=1.79 \times 10^{-12} \exp (-1369 / \mathrm{T}) \mathrm{cm}^{3} \cdot \mathrm{molec}^{-1} \cdot \mathrm{s}^{-1}$ & {$[31]$} \\
\hline $\mathrm{NO}_{2}+\mathrm{O} \rightarrow \mathrm{NO}+\mathrm{O}_{2}$ & $\mathrm{k}=6.51 \times 10^{-12} \exp (120 / \mathrm{T}) \mathrm{cm}^{3} \cdot \mathrm{molec}^{-1} \cdot \mathrm{s}^{-1}$ & {$[31]$} \\
\hline $\mathrm{NO}_{2}+\mathrm{O}_{3} \rightarrow \mathrm{NO}_{3}+\mathrm{O}_{2}$ & $\mathrm{k}=1.4 \times 10^{-13} \exp (-2470 / \mathrm{T}) \mathrm{cm}^{3} \cdot \mathrm{molec}^{-1} \cdot \mathrm{s}^{-1}$ & {$[31]$} \\
\hline $\mathrm{NO}_{2}+\mathrm{OH} \rightarrow \mathrm{HNO}_{3}$ & $\mathrm{k}=2.6 \times 10^{-30}(\mathrm{~T} / 298)^{-2.9} \mathrm{~cm}^{6} \cdot \mathrm{molec}^{-1} \cdot \mathrm{s}^{-1}$ & [31] \\
\hline $\mathrm{NO}_{2}+\mathrm{NO}_{3}+\mathrm{M} \rightarrow \mathrm{N}_{2} \mathrm{O}_{5}+\mathrm{M}$ & $\mathrm{k}=3.7 \times 10^{-30} \mathrm{~T}^{-4.1} \mathrm{~cm}^{6} \cdot \mathrm{molec}^{-2} \cdot \mathrm{s}^{-1}$ & [32] \\
\hline $\mathrm{O}\left({ }^{1} \mathrm{D}\right)+\mathrm{N}_{2} \rightarrow \mathrm{N}_{2} \mathrm{O}$ & $9.02 \times 10^{-37} \mathrm{~cm}^{6} \cdot \mathrm{molec}^{-2} \mathrm{~s}^{-1}$ & {$[31]$} \\
\hline
\end{tabular}

According to the specific thermal behavior of the reactors, a change in the signal frequency was found to have different effects whether it was in the pin-to-pin reactor (Figure 8-a) or in the cylinderto-cylinder reactor (Figure 8-b). For the pin-to-pin reactor, up to a value of input power of 4W (120J/L specific input energy), the frequency had no influence on the ozone concentration measured at the reactor outlet; above 120J/L, the ozone production energy efficiency slightly decreased. For the cylinder-to-cylinder reactor, ozone production was found to be strongly influenced by the pulse voltage frequency even for relatively low specific input energy (e.g. 40J/L). The decrease of ozone production efficiency with increasing frequency is illustrated by Figure 8-c where ozone 
concentration measured at the reactor outlet is plotted as a function of frequency for constant specific input energy for both reactors.
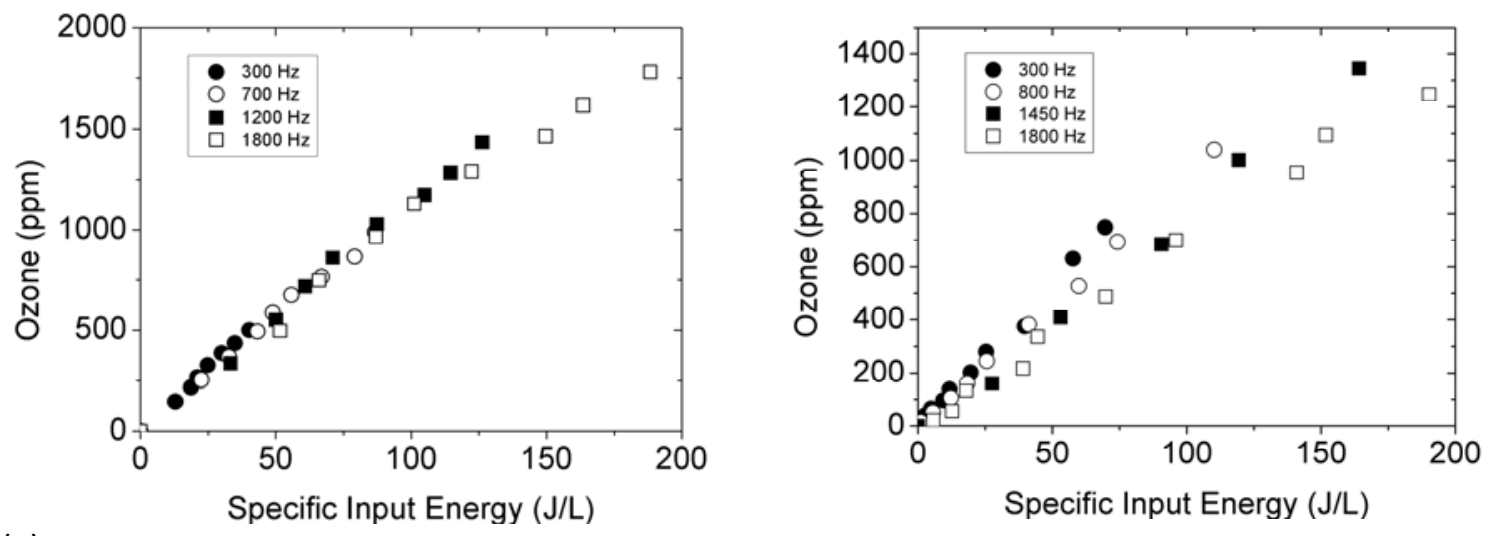

(b)

(a)

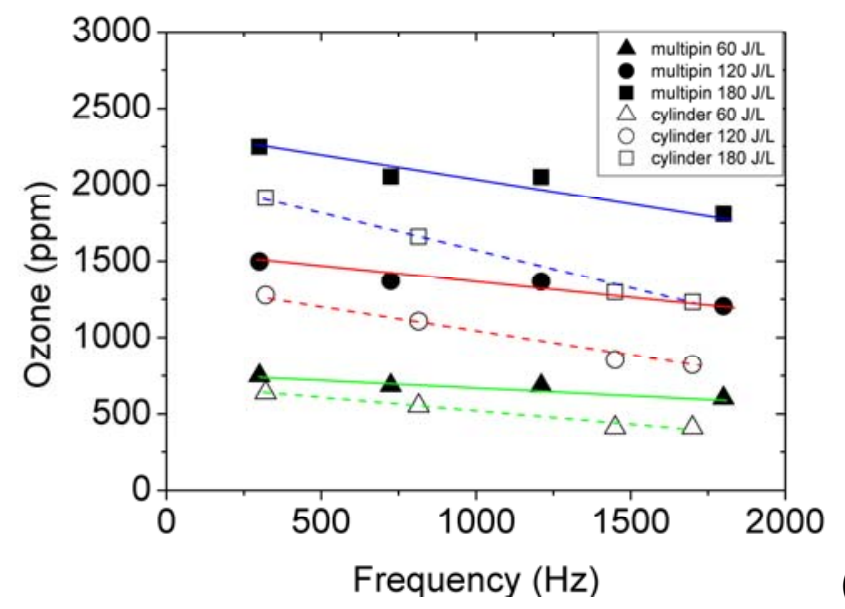

(c)

Figure 8. Ozone production for different pulse frequencies vs. specific input energy (a) in the pin-to-pin reactor

(68 pins, air flow 2 L/min, pulse power supply), (b) in the cylinder-to-cylinder reactor (air flow $2 \mathrm{~L} / \mathrm{mn}$, pulse power supply) and (c) vs. frequency in both conditions for different values of specific input energy.

Ozone production is systematically lower with the cylinder-to-cylinder reactor than with the point-topoint reactor. For a given frequency, the difference in ozone concentration found between the two reactors increases with energy density. At constant energy density, the ozone production decreases with frequency, and the difference between the two reactors increases too.

The fundamental difference between the two reactors is that the number of discharges is set in the case of pin reactor, while in the cylinder-to-cylinder reactor, it is dependent on the frequency. At low frequency, a discharge happens in a large number of filaments spread randomly over the whole 
surface of electrode. When frequency is increased, filaments become less and less numerous due to a more predominant memory effect (a higher frequency will lead to a lower number of discharges due to increasing memory effects - for instance, heating of the gaseous column resulting in a local increase of the reduced field $\mathrm{E} / \mathrm{N}$ ). This change of the filament distribution can have a direct influence on the energy deposition in the gas flow and in particular on the heating of the gas. Results obtained with pulse power supply or bidirectional power supply showed the same trend with respect to the frequency.

This behavior had to be taken into account when comparing the influence of the applied voltage shape on the ozone energy efficiency for the two considered reactor geometries. For most of the following results, a common frequency of $1800 \mathrm{~Hz}$ was chosen, implying a singular behavior for each reactor.

\subsection{Influence of the voltage shape}

Although the reactor geometry is completely different between the pin-to-pin reactor and the cylinder-to-cylinder reactor, the inception voltage for either reactor for the same power supply is on the same order of magnitude.By contrast, a large difference in inception voltage is found between the two types of voltage signals as illustrated in figure 9. Simple calculations of reduced electric field E/N values for discharge inception in the cylinder-to-cylinder reactor corresponding to a $3 \mathrm{~W}$ discharge input power give $160 \mathrm{Td}$ and $400 \mathrm{Td}$ for the bi-directional voltage (inception voltage lower than peak voltage) and the pulse voltage (inception voltage $\sim$ peak voltage), respectively (see Figures $2(b, d)$ ). It is generally assumed that increasing the local $\mathrm{E} / \mathrm{N}$ value shall lead to increase the fraction of electronic collisions which result in dissociation (e.g. oxygen dissociation) rather than excitation phenomena [33]. Such an electronic energy distribution change should lead to the modification of the $\mathrm{O}$ atom production rate and therefore the ozone production efficiency.

A second relevant remark about Figure 9 is that, for the two different voltage shapes, very different peak voltages lead to the same power value being dissipated in the discharge (for the same frequency). The inception voltage in the case of the pulsed voltage is equal to the applied voltage amplitude while the inception voltage is roughly independent of the peak voltage in the case of the bi-directional signal. As a result, for the case of pulsed voltage, a high amplitude, (tens of amperes depending on the voltage pulse amplitude) short duration, (100 ns maximum) isolated current pulse appears, while for the bi-directional signal, a train of relatively low amplitude (hundreds of milliamperes) current peaks develop within a time interval delimited by the inception voltage value and by the peak voltage value. 


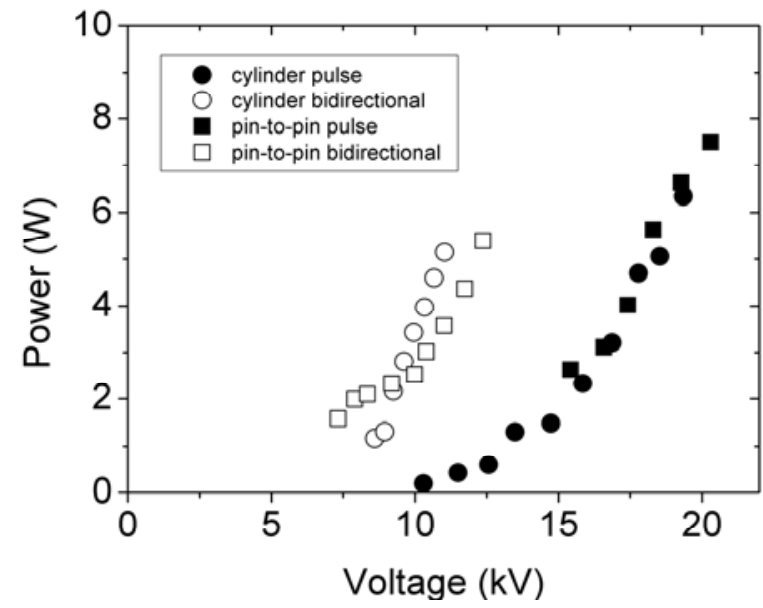

Figure 9. Discharge input power vs. applied voltage amplitude for both reactors (68 pins for the pin-to-pin reactor) energized by both power supplies. - air flow: 2 L/min, pulse power supply and bidirectional power supply: $1800 \mathrm{~Hz}$.

The production of ozone in both the cylinder-cylinder and pin-to-pin reactor is compared for the two electrical power supplies as a function of the specific energy density in Figure 10. As already discussed, ozone production in the pin to pin reactor is slightly superior to that in the cylinder reactor. For a given reactor, the concentration of ozone is found to be independent of the applied voltage shape although the voltage rise rate is one hundred times higher for the pulse power supply than for the bidirectional power supply.

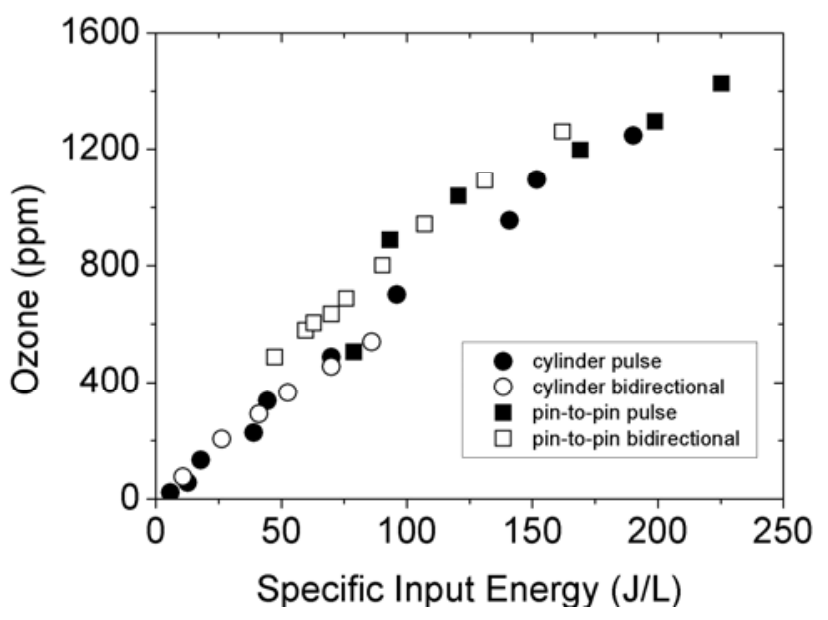

Figure 10. Ozone concentration measured downstream of the reactor vs. specific input energy for both reactors (68 pins for the pin-to-pin reactor) energized by both power supplies - air flow: $2 \mathrm{~L} / \mathrm{min}$, pulse power supply and bidirectional power supply: $1800 \mathrm{~Hz}$. 
By comparing the charge variation as a function of the power for different configurations as shown in Figure 11, it can be seen that for a given reactor, the charge is the same at a given input power for the two power supplies.

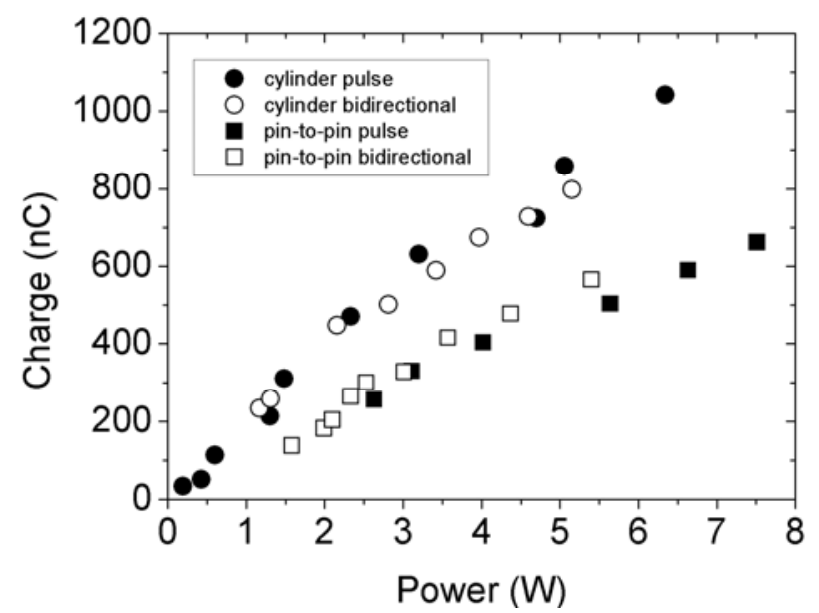

Figure 11. Transferred charge vs. discharge input power for both reactors (68 pins for the pin-to-pin reactor) energized by both power supplies - air flow: 2 L/min, pulse power supply and bidirectional power supply: $1800 \mathrm{~Hz}$.

The important difference between the charge for the pin to pin reactor and the cylinder reactor is due to the difference of gap length and number of discharge filaments in the two reactors (the number of filaments is not controlled in the cylinder-cylinder reactor).

Figure 12 shows the relation between ozone concentration and transferred charge. As stated before [24], a quite linear trend between ozone and the transferred charge exists. For a given reactor and the same electrical charge, ozone production is observed to be independent of the power supply. By comparing the two reactors, the ozone production is higher with the pin-to-pin reactor at a given transferred charge. In other words, the energy cost required to obtain a given charge value is higher in the case of the pin-to-pin reactor, but this charge also leads to a higher ozone production. This remark is of high interest but out of the scope of this work which rather focuses on the influence of the voltage shape on a given reactor than on the comparison between two reactor geometries. 


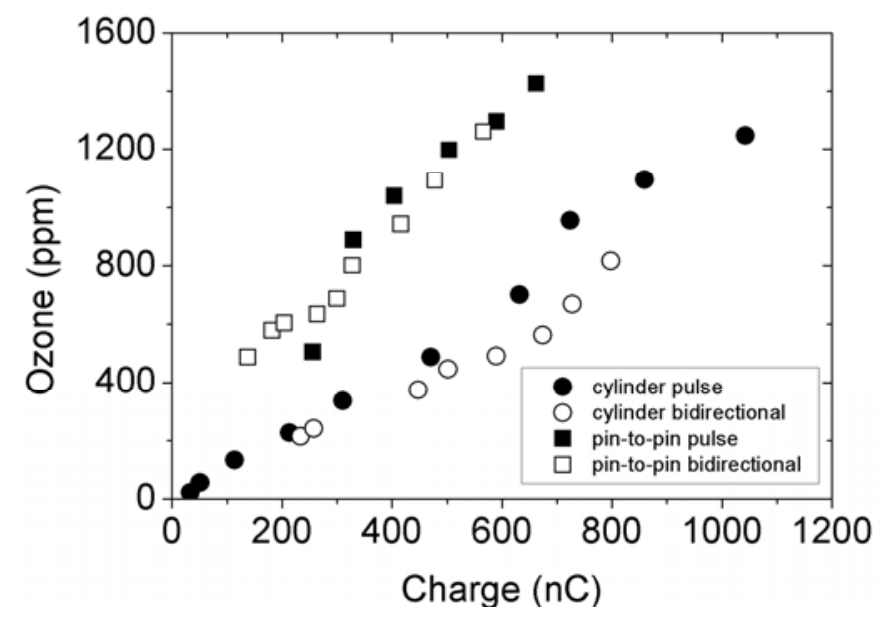

Figure 12. Ozone concentration measured downstream of the reactor vs. transferred charge for both reactors (68 pins for the pin-to-pin reactor) energized by both power supplies; dry air 2L/min.

The similar behavior in a given reactor geometry energized by either the bidirectional power supply or the pulsed power supply for ozone production exists also concerning nitrogen oxides production in the discharge. Figure 13 presents the concentration of nitrogen oxides (dinitrogen pentoxide, nitric acid and nitrous oxide) in the pin-to-pin reactor energized by the bidirectional power supply or the pulsed power supply. The ozone production very similar for the two cases as has been shown previously in figure 10.

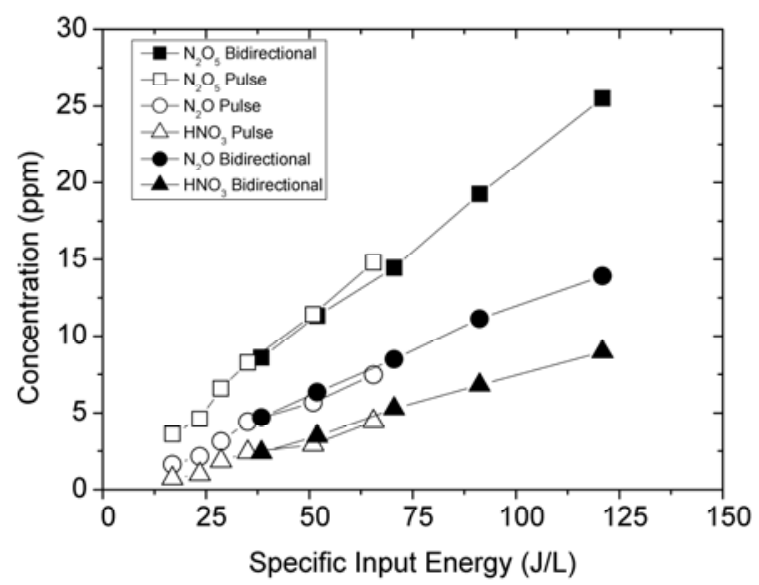

Figure 13. Nitrogen oxides concentrations measured downstream of the reactor vs. specific input energy in the pin-to-pin reactor (16 pins) energized by both power supplies; dry air $2 \mathrm{~L} / \mathrm{min}$.

In order to extend the investigations to a low frequency range, and to confirm the independence of the energy efficiency of the discharge with respect to the voltage rise rate, an experiment was done 
to compare ozone production in the pin-to-pin reactor with a sinusoidal power supply at $50 \mathrm{~Hz}$ and the pulse power supply at $50 \mathrm{~Hz}$. The sinusoidal power supply has a rise rate up to $2.5 \mathrm{kV} / \mathrm{ms}$ that is $2.5 \times 10^{6}$ times slower than the pulse power supply. Figure 14 shows the ozone concentration for these two types of power supply. Again, a similar energy efficiency of ozone production is observed for both the pulsed and the ac power supplies at $50 \mathrm{~Hz}$.

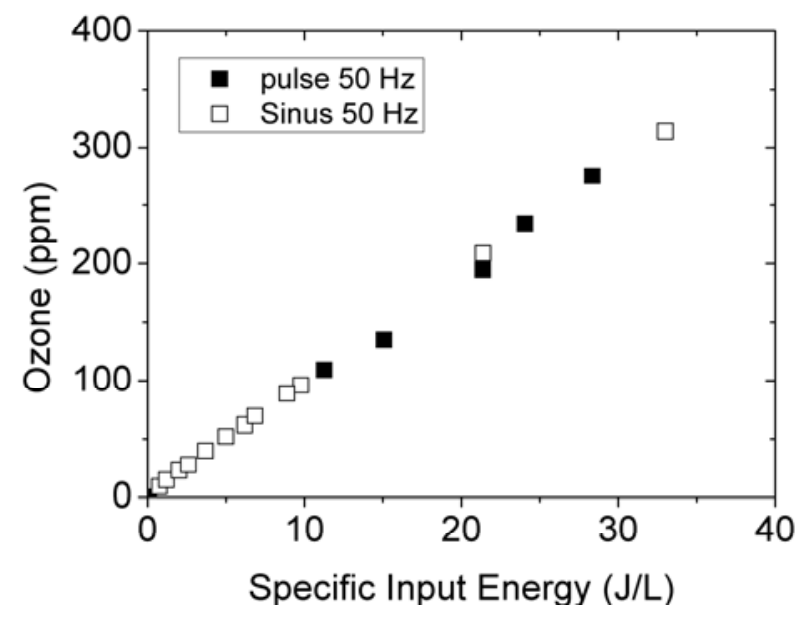

Figure 14. Ozone concentration measured downstream of the reactor vs. specific input energy for the pin-topin reactor (68 pins) energized by a $50 \mathrm{~Hz}$ ac power supply and the pulsed power supply; dry air $1 \mathrm{~L} / \mathrm{min}$.

The influence of the power supply is found to be insignificant for the two investigated DBD reactor geometries indicating that voltage rise rate (in the range considered here) and voltage application duration has no effect on the efficiency in a barrier discharge. The main peculiarity of the insertion of a dielectric inside the discharge is to shorten the current pulse due to charge deposition onto the dielectric. The current peak is self-controlled by the charge deposition and so a reduction of the pulse width has no effect, which is not the case for corona discharge (streamer discharge without dielectric). In others words, the barrier discharge maximizes the energy deposit by self-extinguishing. The unchanged efficiency of dielectric barrier discharge with respect to the voltage waveform was previously observed by Korzekwa et al. [23]. They explained the same plasma efficiency at two different values of reduced field by the fact that oxygen radical production is not linear with the reduced electric field and has a maximum. In their experimental conditions, this would lead to the same radical formation efficiency. Another explanation is that the reduced field experienced by molecules inside the discharge is inferior to that implied by the external field because of space charges and charges on the dielectric surface. In the present experiments, the difference of breakdown voltage between the two power supplies led to different electric field values. These values were different from the ones in [23] and thus allow the dismissal of the hypothesis of the same radical production efficiency at two different values of reduced field. The possibility of 
producing in discharge an average electric field independent of applied voltage was previously demonstrated by Penetrante et al. both theoretically [34] and experimentally [35]. In their experiments, the efficiency of three different discharges for $\mathrm{NO}_{x}$ removal was investigated. Although having much different reduced electric fields, the three reactors had the same efficiency for NOx abatment. For the present experiments, where the possibility of the same radical production at two different values of electric field can be excluded, it can be suggested that the non-improvement of efficiency by overvoltage pulses comes from the fact that the electric field is space-shielded inside the discharge filament.

\section{Conclusion}

This work was intended to clarify the influence of the voltage waveform on the chemical reactivity of dielectric barrier discharges in air at atmospheric pressure. The chemical reactivity was characterized by ozone production efficiency in dry air. Measurement and calculation of the discharge input power were carefully conducted. For each type of applied waveform, power determination was checked by at least two methods, with a good agreement (within $10 \%$ in the worst case). Such an effort on metrology is an important prerequisite due to the large effects on power calculation caused by small measurement errors, especially in the case of the fast rise voltage signal. Conducted on two different reactor geometries, exhibiting different thermal behaviors, the study of the production of ozone in barrier discharges has shown no difference between the use of either bi-directional or pulsed discharge, indicating that changing the voltage duration or the voltage rise rate (in the investigated range) doesn't influence the formation efficiency of reactive species. The barrier quickly limits the electric field in the gap by storing charges on its surface. The effect of the pulsed power supply might be envisaged to only be seen if the voltage duration is inferior to the discharge propagation time, which in present work is inferior to several nanoseconds. The overvoltage value introduced by the use of the pulsed power supply is then insufficient to produce an effect on the gas chemistry. The non influence of the power supply was found for both pin-to-pin and cylinder-cylinder geometry. 


\section{References}

[1] R. McAdams, J. Phys. D: Appl. Phys. 34 (2001) 2810-2821

[2] S. Pasquiers, Eur. Phys. J. Appl. Phys. 28 (2004) 319-324

[3] R. Rudolph, K-P. Francke, H. Miessner, Plasma chemistry and plasma processing 22 (2002) 401-412

[4] U. Kogelschatz, Pure \& Appl. Chem. 62 (1990) 1667-1674

[5] Sz. Beleznai, G. Mihajlik, I. Maros, L. Balazs, P. Richter, J. Phys. D: Appl. Phys. 41 (2008) 115202

[6] H-E Wagner, R. Brandenburg, K.V. Kozlov, A. Sonnenfeld, P. Michel, J.F. Behnke, Vacuum 71 (2003) 417-436

[7] F. Massines, G. Gouda, J. Phys. D: Appl. Phys. 31 (1998) 3411-3420

[8] K. Teranishi, N. Shinomura, S. Suzuki, H. Itoh, Plasma sources Sci. Technol. 18 (2009) 045011

[9] G.J. Pietsch, V.I. Gibalov, Pure \& Appl. Chem. 70 (1998) 1169-1174

[10] H.L. Chen, H.M. Lee, S.H. Chen, T.C. Wei, M.B. Chang, Plasma Sources Sci. Technol. 19 (2010) 055009

[11] L. Hulka, G.J. Pietsch, Plasma Processes and Polymers 2 (2005) 222-226

[12] M.A. Jani, K. Toda, K. Takaki, T. Fujiwara, J. Phys. D : Appl. Phys. 33 (2000) 3078-3082

[13] K. Takaki, Y. Hatanaka, K. Arima, S. Mukaigawa, T. Fujiwara, Vacuum 83 (2009) 128-132

[14] N. Osawa, H. Kaga, Y. Fukuda, S. Harada, Y. Yoshioka, and R. Hanaoka, Eur. Phys. J. Appl. Phys. 55 (2011) 13802

[15] S. Masuda, M.Sato, T. Seki, IEEE Trans. on Industry applications 22 (1986) 886-891

[16] D. Wang, T. Matsumoto, T. Namihira, H. Akiyama, J. Adv. Oxid. Technol. 13 (2010) 71-78

[17] S. Liu, M. Neiger, J. Phys. D : Appl. Phys. 34 (2001) 1632-1638

[18] J. Salge, P. Braumann, in Proceedings of the $4^{\text {th }}$ Int. Symp. On Plasma Chemistry, Zurich,1979 p. $735-741$

[19] J.M. Williamson, D.D. Trump, P. Bletzinger, B.N. Ganguly, J.Phys. D : Appl. Phys. 39 (2006) 4400-4406

[20] K. Okazaki, T. Nozaki, Pure Appl. Chem. 74 (2002) 447-452

[21] H. Wong, D. Li, Y. Wu, J. Li, G. Li, J. of Electrostatics 67 (2009) 547-553

[22] S.L. Yao, E. Suzuki, N. Meng, A. Nakayama, Energy and Fuels 15 (2001) 1300-1303 
[23] R. Korzekwa, L. Rosocha, Z. Falkenstein, in Proceedings of the Eleventh IEEE International Pulsed Power Conference, Baltimore Maryland, 1997

[24] E. Odic, M. Dhainault, M. Petit, A. Goldman, M. Goldman, C. Karimi, J. Adv. Oxid. Technol. 6 (2003) 41-47

[25] A. Mfopara, M.J. Kirkpatrick, E. Odic, Plasma Chem. Plasma Process 29 (2009) 91-102

[26] L. Parissi, E. Odic , A. Goldman, M. Goldman and J-P. Borra, Chapter 11: Temperature effects on plasma chemical reactions. Application to VOC removal from flue gases by dielectric barrier discharges, in Electrical Discharges for Environmental Purposes : Fundamentals and Applications, E. M. v. Veldhuizen ed., Nova Science Publishers, New York, 2000.

[27] I. Stefanovic, N.K. Bibinov, A.A. Deryugin, I.P. Vinogradov, A.P. Napartovich, K. Wiesemann, Plasma Sources Sci. Technol. 10 (2001) 406-416

[28] S. Hadj-Ziane, B. Held, P.Pignolet, R. Peyrous, C. Coste, J. Phys. D:Appl. Phys 25 (1992) 677685

[29] R. Atkinson, D.L Baulch, R.A Cox, R.F. Hampson, J.A. Kerr, J. Troe, J. Phys. Chem. Ref. Data 18 (1989) 881-1097

[30] I.M. Campbell, C.N. Gray, Chem. Phys. Lett. 18 (1973) 607

[31] R. Atkinson, D.L Baulch, R.A Cox, R.F. Hampson, J.A. Kerr, M.J. Rossi, J. Troe, J. Phys. Chem. Ref. Data 26 (1997) 521

[32] R. Atkinson, D.L. Baulch, R.A. Cox, J.N. Crowley, R.F. Hampson, R.G. Hynes, M.E. Jenkin, M.J. Rossi, J. Troe, Atmos. Chem. Phys. 4 (2004) 1461-1738

[33] G.J.M. Hagelaar, L.C. Pitchford, Plasma Sources Sci. Technol. 14 (2005) 722-733

[34] P.A. Vitello, B.M. Penetrante, J.N. Bardsley, in Non-thermal Plasma techniques for pollution control - Part A : Overview, fundamentals and supporting technologies, B.M. Penetrante and S.E. Schultheis,( Eds. Berlin; Springer-Verlag, 1993), pp 249-271

[35] B.M. Penetrante, M.C. Hsiao, B.T. Merritt, G.E. Vogtlin, P.H. Wallman, IEEE Trans. On Plasma Science 23 (1995) 679-687 


\section{List of figure and table captions:}

Figure 1. Schematics and photographs of the plasma reactors (a) pin-to-pin DBD reactor, (b) co-axial cylinderto-cylinder DBD reactor.

Figure 2. Voltage and current waveforms obtained with the bi-directional power supply (a-b) and pulsed power supply (c-d) coupled with the pin-to-pin DBD reactor.

Figure 3. FTIR spectrum obtained at the pin-to-pin discharge reactor outlet, with the bi-directional power supply $(2.35 \mathrm{~W}, \mathrm{f}=3685 \mathrm{~Hz})$; dry air $2 \mathrm{~L} / \mathrm{min}$.

Figure 4. Lissajous figure corresponding to $4 \mathrm{~W}$ input power dissipated in the pin-to-pin reactor (air flow $2 \mathrm{~L} / \mathrm{min}$., bi-directional power supply, $\mathrm{f}=1540 \mathrm{~Hz}$ ).

Figure 5. Current and voltage signals obtained with the pin-to-pin reactor and the pulse power supply (a) and raw current signal divided into its two components, displacement current and discharge current (b).

Figure 6. Applied voltage and charge signals (a) obtained with the pin-to-pin reactor and the pulse power supply (4.7 $\mathrm{nF}$ measurement capacitor in series with the counter electrode); (b) corresponding $\mathrm{V}$-Q figure.

Figure 7. Ozone concentration at the reactor outlet vs. specific input energy, for the cylinder-to-cylinder reactor and for the pin-to-pin reactor (with increasing number of pins from 16 to 104) - air flow: 2 L/min, bi-directional power supply, $1450 \mathrm{~Hz}$ for the pin-to-pin reactor, $1700 \mathrm{~Hz}$ for the cylinder-to-cylinder reactor.

Figure 8. Ozone production for different pulse frequencies vs. specific input energy (a) in the pin-to-pin reactor (68 pins, air flow $2 \mathrm{~L} / \mathrm{mn}$, pulse power supply), (b) in the cylinder-to-cylinder reactor (air flow $2 \mathrm{~L} / \mathrm{min}$, pulse power supply) and (c) vs. frequency in both conditions for different values of specific input energy.

Figure 9. Discharge input power vs. applied voltage amplitude for both reactors (68 pins for the pin-to-pin reactor) energized by both power supplies. - air flow: 2 L/min, pulse power supply and bidirectional power supply: $1800 \mathrm{~Hz}$.

Figure 10. Ozone concentration measured downstream of the reactor vs. specific input energy for both reactors (68 pins for the pin-to-pin reactor) energized by both power supplies - air flow: $2 \mathrm{~L} / \mathrm{min}$, pulse power supply and bidirectional power supply: $1800 \mathrm{~Hz}$.

Figure 11. Transferred charge vs. discharge input power for both reactors (68 pins for the pin-to-pin reactor) energized by both power supplies - air flow: 2 L/min, pulse power supply and bidirectional power supply: $1800 \mathrm{~Hz}$.

Figure 12. Ozone concentration measured downstream of the reactor vs. transferred charge for both reactors (68 pins for the pin-to-pin reactor) energized by both power supplies; dry air 2L/min. 
Figure 13. Nitrogen oxides concentrations measured downstream of the reactor vs. specific input energy in the pin-to-pin reactor (16 pins) energized by both power supplies; dry air 2L/min.

Figure 14. Ozone concentration measured downstream of the reactor vs. specific input energy for the pin-topin reactor (68 pins) energized by a $50 \mathrm{~Hz}$ ac power supply and the pulsed power supply; dry air $1 \mathrm{~L} / \mathrm{min}$.

Table 1: reactions and rate constants for ozone and nitrogen oxides formation 
Figures

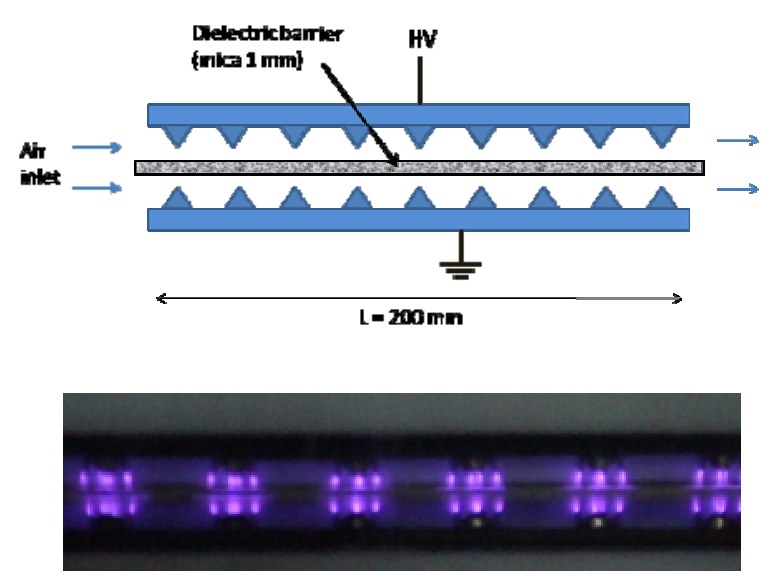

(a)
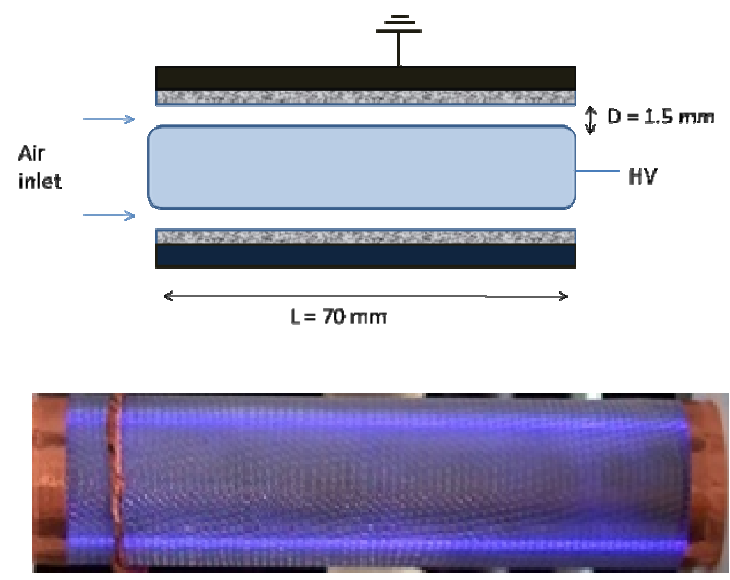

(b)

Figure 1. 


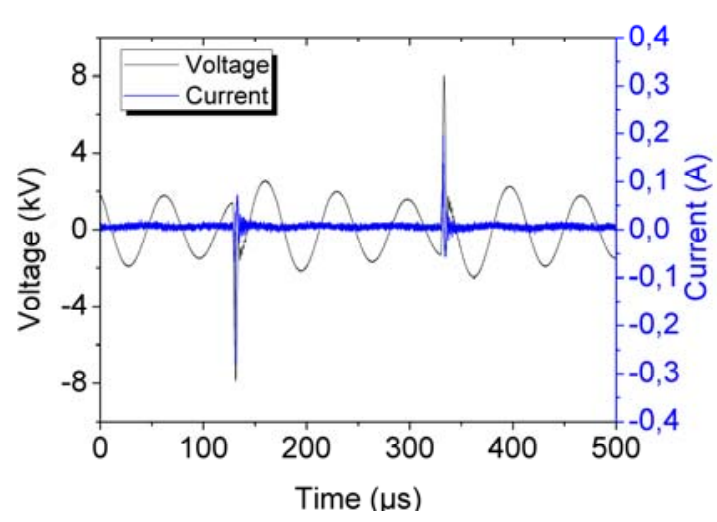

(a)

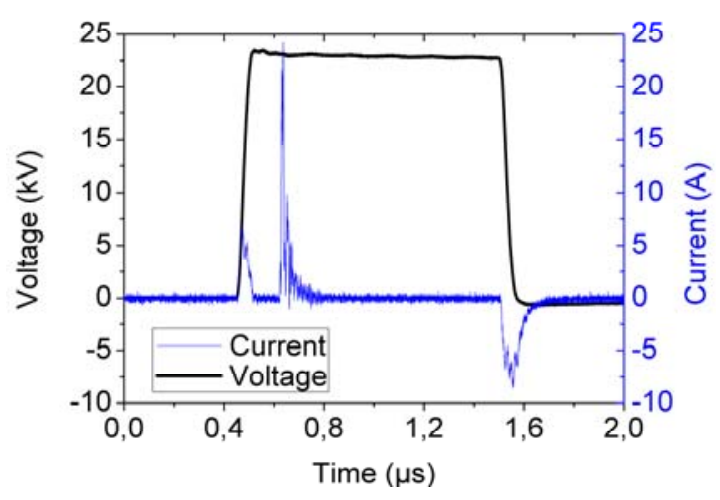

(c)

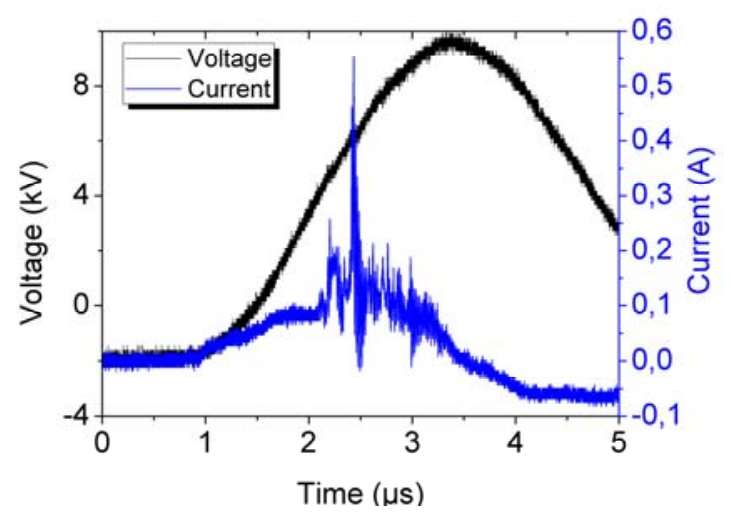

(b)

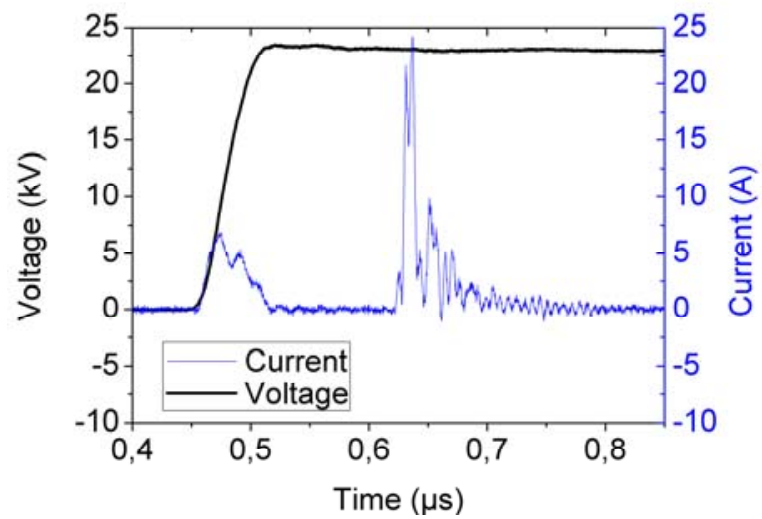

(d)

Figure 2 .

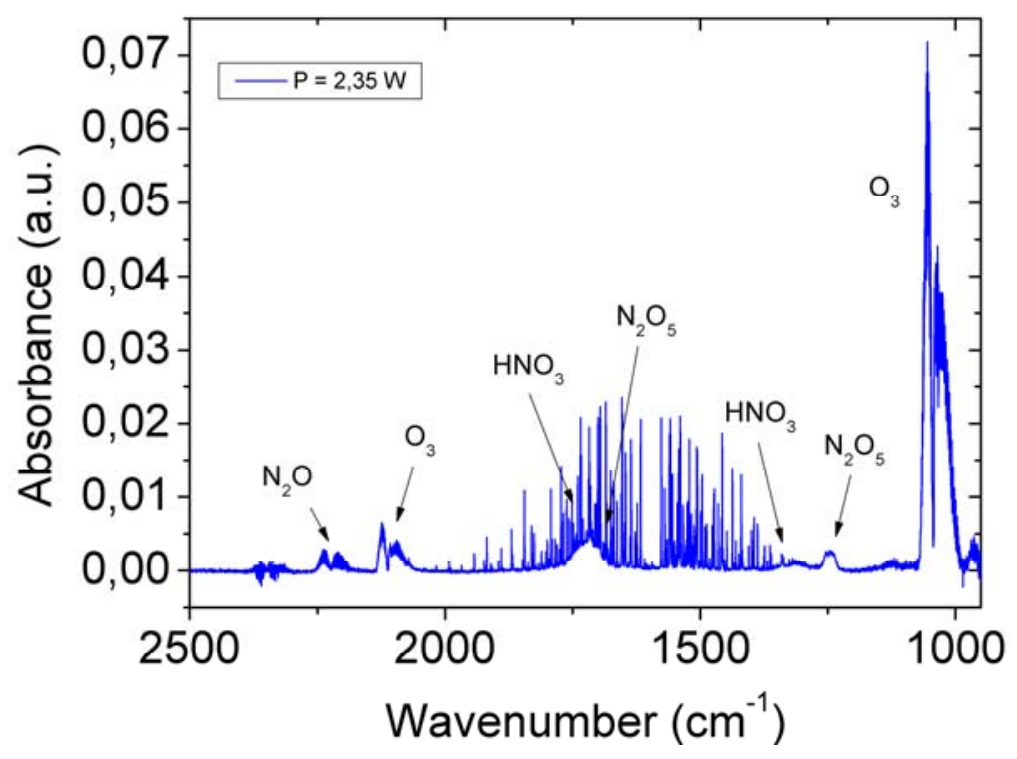

Figure 3. 


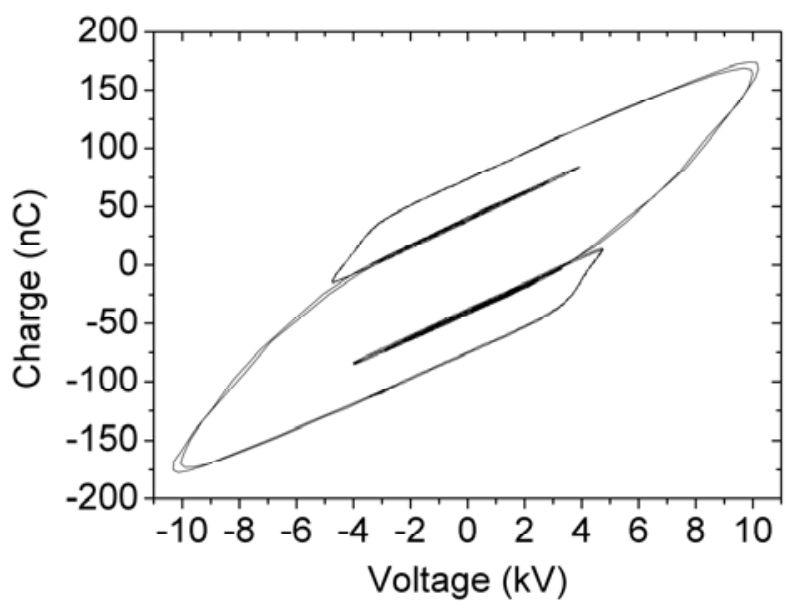

Figure 4.
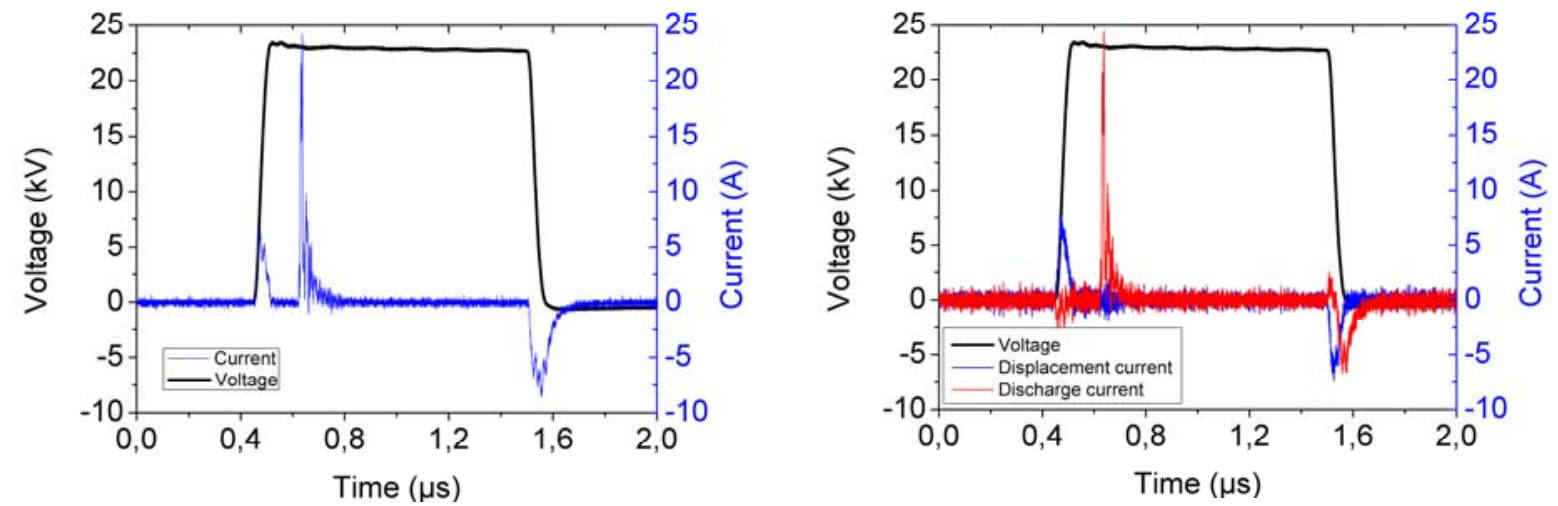

(a)

(b)

Figure 5.

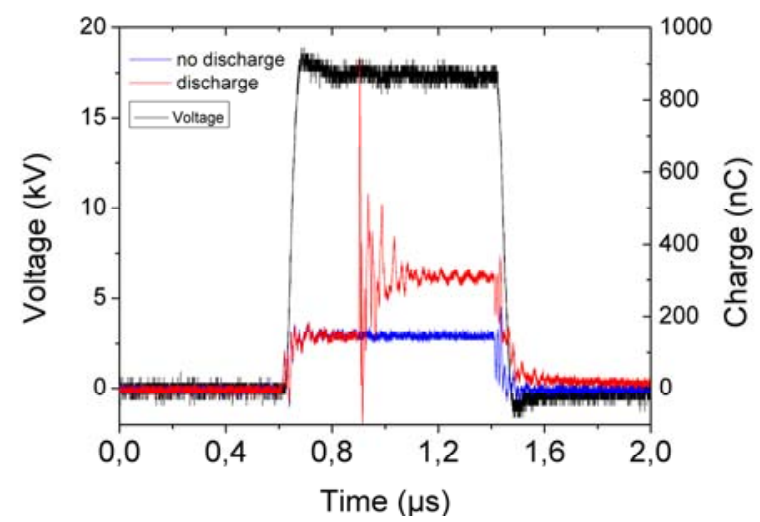

(a)

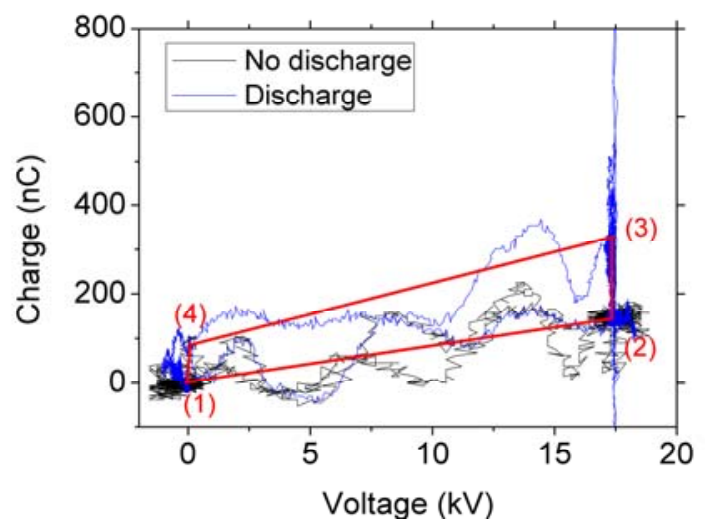

(b)

Figure 6. 


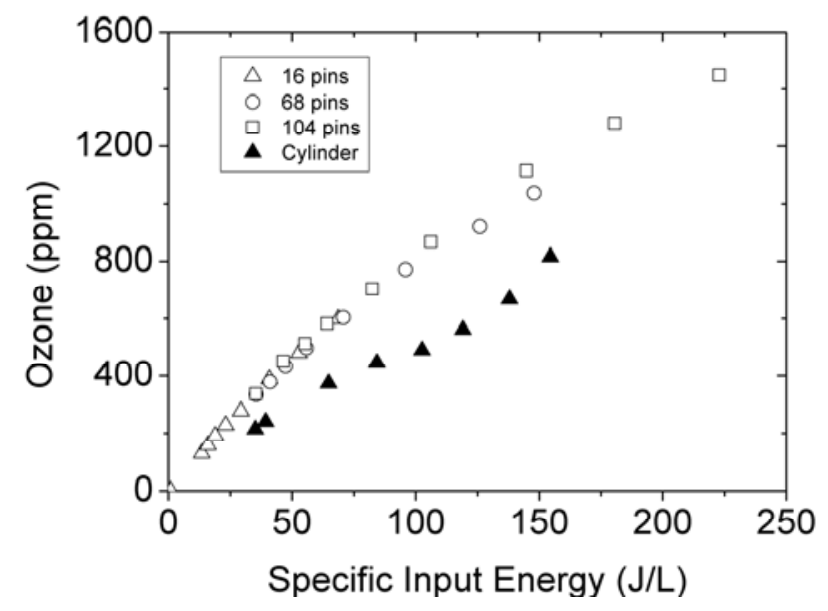

Figure 7.
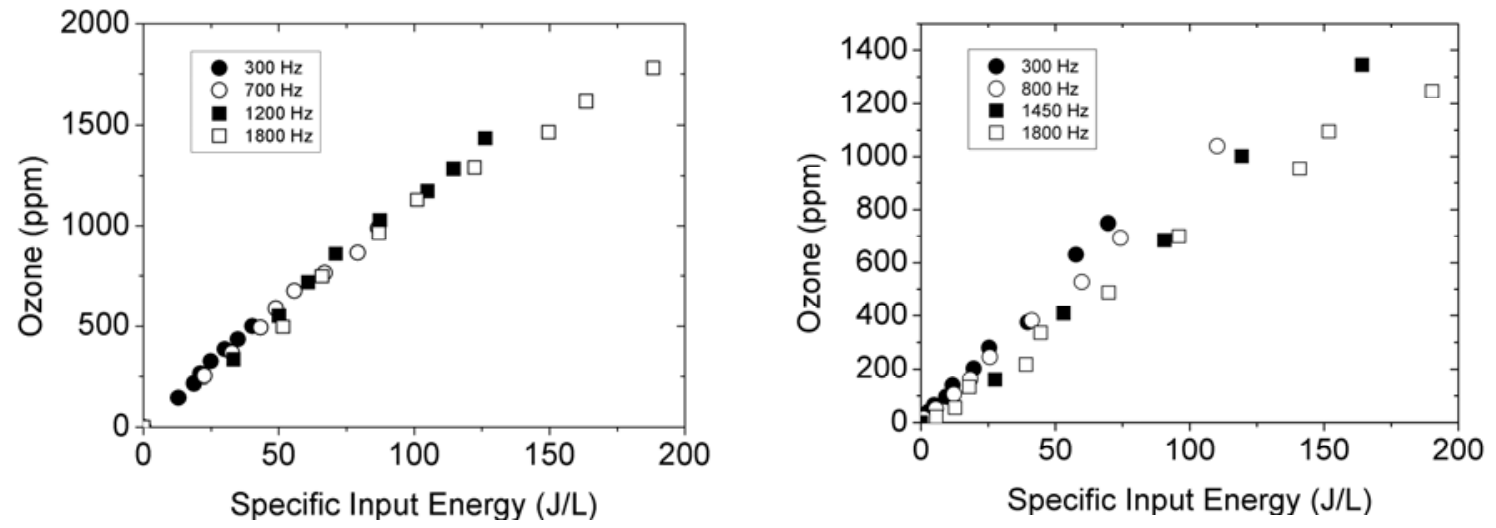

(b)

(a)

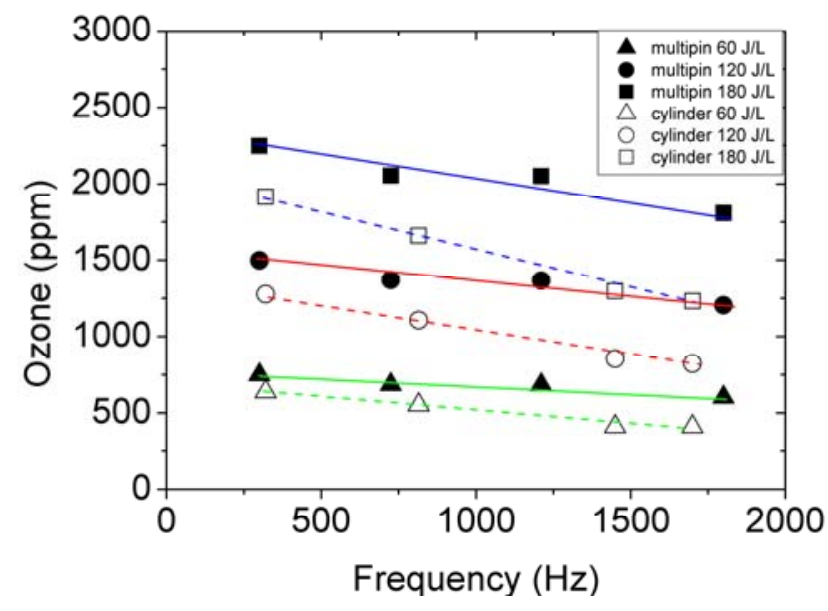

(c)

Figure 8. 


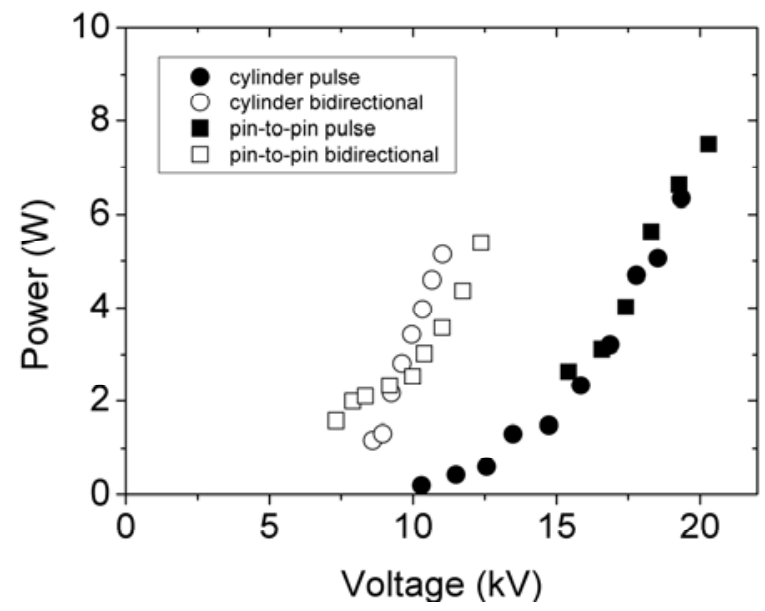

Figure 9.

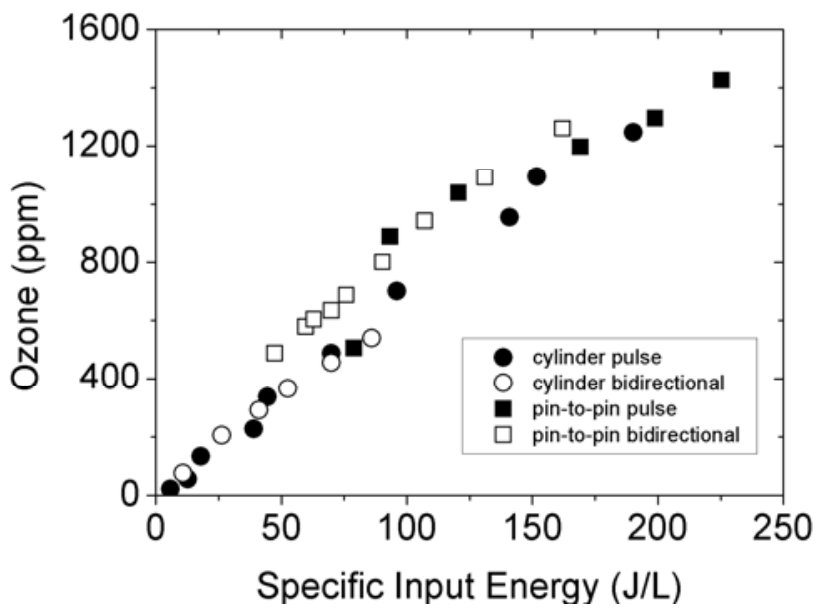

Figure 10.

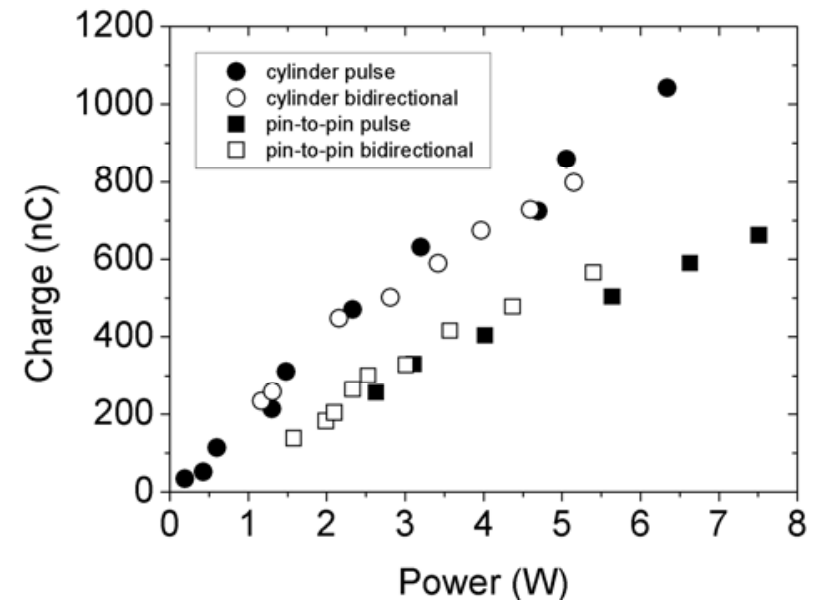

Figure 11. 


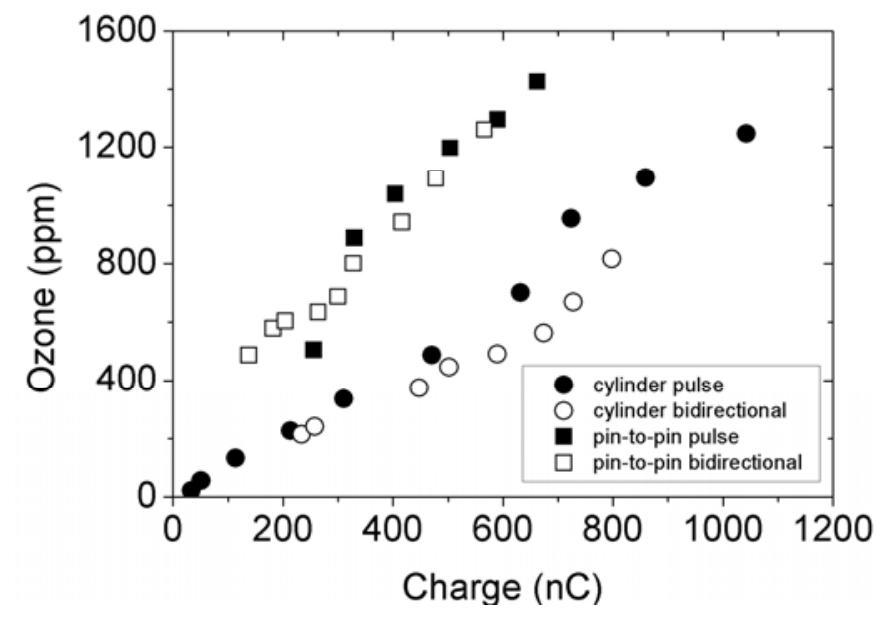

Figure 12.

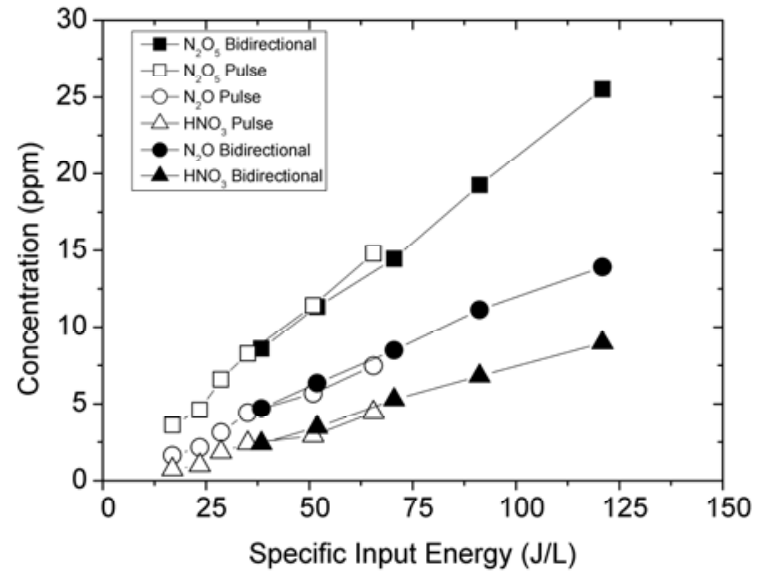

Figure 13.

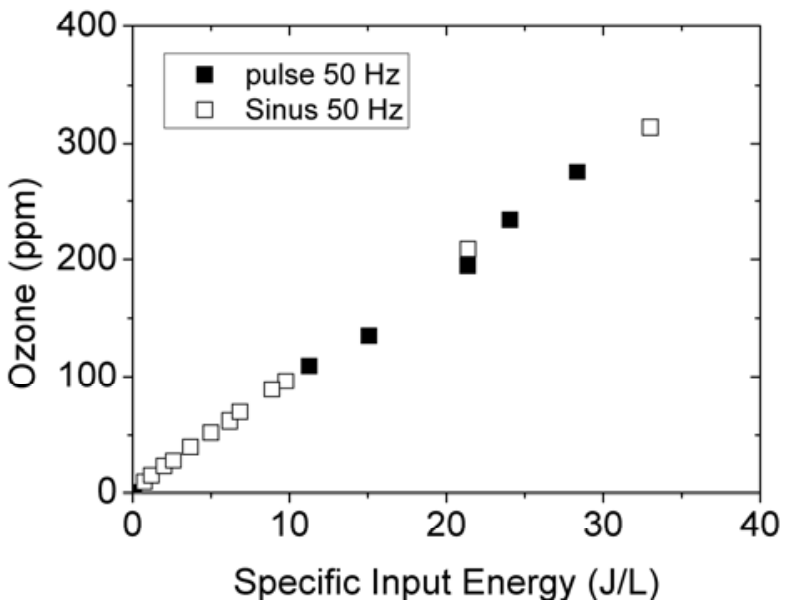

Figure 14. 


\begin{tabular}{|c|c|c|}
\hline Process & Rate coefficient & Reference \\
\hline $\mathrm{O}+\mathrm{O}_{2}+\mathrm{M} \rightarrow \mathrm{O}_{3}+\mathrm{M}$ & $\begin{array}{ll}\mathrm{M}=\mathrm{O}_{2} & \mathrm{k}=5.58 \times 10^{-29} \mathrm{~T}^{-2} \mathrm{~cm}^{6} \cdot \mathrm{molec}^{-2} \cdot \mathrm{s}^{-1} \\
\mathrm{M}=\mathrm{N}_{2} & \mathrm{k}=8.6 \times 10^{-31} \mathrm{~T}^{-1.25} \mathrm{~cm}^{6} \cdot \mathrm{molec}^{-2} \cdot \mathrm{s}^{-1}\end{array}$ & $\begin{array}{l}{[27]} \\
{[27]}\end{array}$ \\
\hline $\mathrm{O}+\mathrm{O}+\mathrm{O}_{2} \rightarrow \mathrm{O}_{2}+\mathrm{O}_{2}$ & $\mathrm{k}=(3.8 / \mathrm{T}) \times 10^{-30} \mathrm{~T}^{-1} \exp (-170 / \mathrm{T}) \mathrm{cm}^{6} \cdot \mathrm{molec}^{-2} \cdot \mathrm{s}^{-1}$ & {$[28]$} \\
\hline $\mathrm{O}_{2}+\mathrm{O}_{3} \rightarrow \mathrm{O}_{2}+\mathrm{O}_{2}+\mathrm{O}$ & $\mathrm{k}=7.3 \times 10^{-10} \exp (-11400 / \mathrm{T}) \mathrm{cm}^{3} \cdot \mathrm{molec}^{-1} \cdot \mathrm{s}^{-1}$ & {$[28]$} \\
\hline $\begin{array}{l}\mathrm{N}+\mathrm{O}_{2} \rightarrow \mathrm{NO}+\mathrm{O} \\
\mathrm{O}+\mathrm{N}+\mathrm{M} \rightarrow \mathrm{NO}+\mathrm{M}\end{array}$ & $\begin{array}{l}\mathrm{k}=4.4 \times 10^{-12} \exp (-3219 / \mathrm{T}) \mathrm{cm}^{3} \cdot \mathrm{molec}^{-1} \cdot \mathrm{s}^{-1} \\
\mathrm{k}=5.46 \times 10^{-33} \pm 4.96 \times 10^{-34} \exp (-1.29 / \mathrm{RT}) \mathrm{cm}^{6} \cdot \mathrm{molec}^{-2} \cdot \mathrm{s}^{-1}\end{array}$ & $\begin{array}{l}{[29]} \\
{[30]}\end{array}$ \\
\hline $\mathrm{N}+\mathrm{O}_{3} \rightarrow \mathrm{NO}+\mathrm{O}_{2}$ & $\mathrm{k}=1.0 \times 10^{-16} \mathrm{~cm}^{3} \cdot \mathrm{molec}^{-1} \cdot \mathrm{s}^{-1}$ & {$[29]$} \\
\hline $\mathrm{NO}+\mathrm{O}_{3} \rightarrow \mathrm{NO}_{2}+\mathrm{O}_{2}$ & $\mathrm{k}=1.79 \times 10^{-12} \exp (-1369 / \mathrm{T}) \mathrm{cm}^{3} \cdot \mathrm{molec}^{-1} \cdot \mathrm{s}^{-1}$ & {$[31]$} \\
\hline $\mathrm{NO}_{2}+\mathrm{O} \rightarrow \mathrm{NO}+\mathrm{O}_{2}$ & $\mathrm{k}=6.51 \times 10^{-12} \exp (120 / \mathrm{T}) \mathrm{cm}^{3} \cdot \mathrm{molec}^{-1} \cdot \mathrm{s}^{-1}$ & {$[31]$} \\
\hline $\mathrm{NO}_{2}+\mathrm{O}_{3} \rightarrow \mathrm{NO}_{3}+\mathrm{O}_{2}$ & $\mathrm{k}=1.4 \times 10^{-13} \exp (-2470 / \mathrm{T}) \mathrm{cm}^{3} \cdot \mathrm{molec}^{-1} \cdot \mathrm{s}^{-1}$ & {$[31]$} \\
\hline $\mathrm{NO}_{2}+\mathrm{OH} \rightarrow \mathrm{HNO}_{3}$ & $\mathrm{k}=2.6 \times 10^{-30}(\mathrm{~T} / 298)^{-2.9} \mathrm{~cm}^{6} \cdot$ molec $^{-1} \cdot \mathrm{s}^{-1}$ & {$[31]$} \\
\hline $\mathrm{NO}_{2}+\mathrm{NO}_{3}+\mathrm{M} \rightarrow \mathrm{N}_{2} \mathrm{O}_{5}+\mathrm{M}$ & $\mathrm{k}=3.7 \times 10^{-30} \mathrm{~T}^{-4.1} \mathrm{~cm}^{6} \cdot \mathrm{molec}^{-2} \cdot \mathrm{s}^{-1}$ & {$[32]$} \\
\hline $\mathrm{O}\left({ }^{1} \mathrm{D}\right)+\mathrm{N}_{2} \rightarrow \mathrm{N}_{2} \mathrm{O}$ & $9.02 \times 10^{-37} \mathrm{~cm}^{6} \cdot \mathrm{molec}^{-2} \mathrm{~s}^{-1}$ & [31] \\
\hline
\end{tabular}

Table 1 